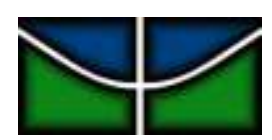

UnB

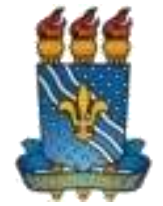

UFPB

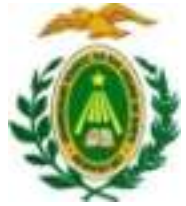

UFRN

UNIVERSIDADE DE BRASÍLIA - UnB

UNIVERSIDADE FEDERAL DA PARAÍBA - UFPB

UNIVERSIDADE FEDERAL DO RIO GRANDE DO NORTE - UFRN

Programa Multiinstitucional e Inter-Regional de Pós-Graduação em Ciências Contábeis

POLYANDRA ZAMPIERE PESSOA DA SILVA

ANÁLISE DO EFEITO DA INCERTEZA SOBRE O NÍVEL DE INVESTIMENTOS: uma abordagem sob a ótica da Teoria das Opções Reais 


\section{ANÁLISE DO EFEITO DA INCERTEZA SOBRE O NÍVEL DE INVESTIMENTOS: uma abordagem sob a ótica da Teoria das Opções Reais}

Dissertação $\mathrm{n}^{\circ} 304$ apresentada ao Programa Multiinstitucional e Inter-Regional de PósGraduação em Ciências Contábeis da Universidade de Brasília (UnB), da Universidade Federal da Paraíba (UFPB) e da Universidade Federal do Rio Grande do Norte (UFRN), em cumprimento às exigências para obtenção do grau de Mestra em Ciências Contábeis.

Orientador: Prof. Dr. Márcio André Veras Machado.

Linha de pesquisa: Contabilidade e Mercado Financeiro. 
S586a Silva, Polyandra Zampiere Pessoa da.

Análise do efeito da incerteza sobre a nível de

investimentos: uma abordagem sob a ótica da Teoria das

Opções Reais / Polyandra Zampiere Pessoa da Silva.- João Pessoa, 2016.

$74 f$.

Orientador: Márcio André Veras Machado

Dissertação (Mestrado) - UFPB/CCSA

1. Contabilidade. 2. Mercado financeiro. 3. Investimento.

4. Incerteza. 5. Teoria das Opções Reais. 


\section{ANÁLISE DO EFEITO DA INCERTEZA SOBRE O NÍVEL DE INVESTIMENTOS: uma abordagem sob a ótica da Teoria das Opções Reais}

Dissertação $n^{\circ} 304$ apresentada ao Programa Multiinstitucional e Inter-Regional de PósGraduação em Ciências Contábeis da Universidade de Brasília, da Universidade Federal da Paraíba e da Universidade Federal do Rio Grande do Norte, em cumprimento às exigências para a obtenção do grau de Mestra em Ciências Contábeis.

COMISSÃO AVALIADORA:

Prof. Dr. Márcio André Veras Machado

Programa Multiinstitucional e Inter-regional de Pós-graduação em Ciências Contábeis da UnB/UFPB/UFRN

Orientador

\section{Prof. Dr. Paulo Aguiar do Monte}

Programa Multiinstitucional e Inter-Regional de Pós-Graduação em Ciências Contábeis da UnB/UFPB/UFRN

Membro Examinador Interno

Prof. Dr. Sinézio Fernandes Maia

Universidade Federal da Paraíba - UFPB

Membro Examinador Externo 
A Deus, pela graça de perseverar sempre e nunca desistir. Â minha família, por toda compreensão e apoio. Dedico. 


\section{AGRADECIMENTOS}

A Deus, por todas as oportunidades que a mim são concedidas, bem como por me proporcionar coragem e disposição para concretizar meus objetivos.

À minha família, em especial à minha mãe, por sempre me apoiarem e entenderem minha ausência.

Ao meu noivo, Márcio Pessoa, pelo carinho e compreensão.

Ao professor e orientador Márcio Machado, pela paciência, orientação segura e todos os ensinamentos.

Ao professor Sinézio Maia, por permitir que acompanhasse suas aulas durante o período de estágio docência e por todos os seus ensinamentos. Suas contribuições foram essenciais para o meu crescimento profissional. Muito obrigada!

Aos professores Anderson Mól e Paulo Aguiar, pelas sugestões recebidas durante a fase de qualificação da dissertação, e novamente, aos professores Sinézio Maia e Paulo Aguiar que aceitaram fazer parte da banca de defesa da dissertação e suas contribuições.

A todos os professores do Programa Multiinstitucional e Inter-Regional de Pós-Graduação em Ciências Contábeis UnB/UFPB/UFRN, que participaram da minha formação: Adilson Tavares, Adriano Paixão, Aneide Araújo, Edilson Paulo, Jorge Katsumi, Márcia Reis, Marcio Machado, Paulo Amilton, Paulo Aguiar, Paulo Roberto e Wenner Gláucio.

Aos meus professores da graduação, Jassuipe Morais, Isabelle Rezende e Dimmitri Morant, que me apresentaram a pesquisa e me direcionaram durante a graduação.

Aos colegas da Turma 28: Ana Carla, Carlos André, Inajá Alanne, Marcelo Paulo, Victor Ranieri, Victor Godeiro, Agamenon da Costa, Roberto José, Leandro Saraiva, Fabiana Lucena e Camila Catarine. Em especial a Victor Ranieri, por sua amizade e apoio durante todo o curso.

A Suelle Cariele, por sempre estar disposta a me ouvir, por seus ensinamentos e por suas palavras de conforto.

Aos amigos Maria Audenora, Gilberto e Emanoel, por todos os momentos de descontração e apoio.

Aos eternos amigos Andrezza, Mayara, Priscila, Rafaela, Roosevelt, Suênia, Tainá e Ykeda, por "compreenderem" minha ausência. Em especial à moça bonita, Rafaela, por ter me acolhido com gentileza e alegria em sua residência.

À Coordenação de Aperfeiçoamento de Pessoal de Nível Superior (CAPES), pelo apoio financeiro.

A todos aqueles que me incentivaram e me apoiaram. 


\section{RESUMO}

Esta dissertação teve por objetivo analisar o efeito da incerteza sobre o nível de investimento das empresas listadas na Bolsa de Valores, Mercadorias e Futuros de São Paulo (BM\&FBovespa). A amostra compôs-se de todas as empresas não financeiras listadas na BM\&FBovespa entre o período de 2008 a 2014. Coletaram-se os dados contábeis e de mercado no banco de dados Economatica ${ }^{\circledR}$, e fez-se a classificação dos setores das empresas de acordo com os dados disponibilizados na BM\&FBovespa. Como proxy para a incerteza total,utilizou-sea volatilidade histórica do retorno das ações. Decompôs-se essa medida em três componentes de risco: o de mercado, o idiossincrático e o específico da firma, baseandose no modelo de Bulan (2005) e Xu, Wang e Xin (2010). Além disso, utilizou-seuma proxy alternativa para medição da incerteza, conforme o estudo de Tran (2014), que foi a volatilidade condicional do retorno das ações. Para análise do efeito da incerteza sobre as decisões de investimento,utilizou-se o método de Mínimos Quadrados Ordinários (MQO) e Mínimos Quadrados em Dois Estágios (MQ2E), quando constatados problemas de endogeneidade da medida de incerteza. Os resultados indicam que a incerteza total tem um efeito negativo e significativo estatisticamente sobre o nível de investimento. Quanto às incertezas de mercado e idiossincrática, verificou-se que não há um efeito estatisticamente significativo sobre o nível de investimento, enquanto que a incerteza específica tem um efeito negativo e significativo, inclusive superior ao da incerteza total, uma vez que o aumento de $1 \%$ da incerteza específica da firma reduz o nível de investimento em $0,4706 \%$, e o aumento de $1 \%$ da incerteza total reduz o nível de investimento em apenas 0,2567\%.Assim, pode-se afirmar que a incerteza da firma é mais significante para explicar o nível de investimento de uma empresa do que a incerteza total, logo, a abordagem que explica o efeito da incerteza sobre o nível de investimento é a Teoria das Opções Reais (TOR).Diante dessas evidências, rejeitaram-se a hipótese 1 , de que a incerteza de mercado tem um efeito negativo sobre o nível de investimento, e a hipótese 2 (a), de que a incerteza idiossincrática tem um efeito negativo sobre o nível de investimento. Por outro lado, não se pode rejeitar a hipótese 2, de que existe um efeito negativo da incerteza total sobre o nível de investimento, e a hipótese 2 (b), de que existe um efeito negativo da incerteza específica da firma sobre o nível de investimento. Além disso, de acordo com os resultados obtidos, verificou-se que, no mercado brasileiro, as firmas menores são mais sensíveis à incerteza e às mudanças no ambiente de negócio do que as firmas maiores. Quanto à competitividade, identificou-se que as empresas mais competitivas são mais sensíveis à incerteza do que as menos competitivas. Ademais, a amostra do estudo se restringiu ao período de fullIFRS, tendo em vista as mudanças das práticas contábeis que alteraram a forma de mensuração de algumas variáveis explicativas. Dessa forma, após essa restrição, verificou-se que não houve variação do efeito das incertezas total, de mercado, de setor e específica da firma sobre o nível de investimento. Nesse sentido, com base nos resultados obtidos, observou-se que a incerteza tem um efeito negativo sobre o nível de investimento das empresas, principalmente a incerteza específica da firma, conforme prevê aTOR.Logo, os administradores devem considerá-la no processo de tomada de decisão. Ressalta-se que esses resultados podem fomentar o estabelecimento de políticas para análise da viabilidade de novos projetos de investimento.Por fim, as conclusões obtidas nesta dissertação devem ficar restritas à amostra utilizada.

Palavras-chave: Investimento. Incerteza. Teoria das Opções Reais. 


\begin{abstract}
This dissertation aimed to analyze the effect of uncertainty on the level of investment by companies listed on the São Paulo Stock, Mercantile and Futures Exchange (BM\&FBovespa). The sample consists of all non-financial companies listed on the BM \& FBovespa between 2008 and 2014. They were collected accounting and market data in Economatica ${ }^{\circledR}$ database, and the classification of sectors of the companies was made according to the data available on the BM\&FBovespa. As a proxy for the total uncertainty, it was used the historical volatility of stock returns. This measure was decomposed into three risk components: market, idiosyncratic and specific to the firm, based on the model of Bulan (2005) and $\mathrm{Xu}$, Wang and Xin (2010). In addition, it was used an alternative proxy to measurement the uncertainty, according to the study of Tran (2014), which was the conditional volatility of the stock return.To analyze the effect of uncertainty on investment decisions, it was used the method of Ordinary Least Squares (OLS) and Two-Stage Least Squares (2SLS), when observed endogeneity problems of measurement of uncertainty.The results indicate that the total uncertainty has a statistically negative and significant effect on the level of investment.Regarding the market and idiosyncraticuncertainties, it was found there is no statistically significant effect on the level of investment, whereas the specific uncertainty has a significant negative effect, even higher than the total uncertainty, since the increase of $1 \%$ of the specific firm uncertainty reduces the level of investment in $0.4706 \%$, and the increase of $1 \%$ of the total uncertainty reduces the level of investment in just $0.2567 \%$. So it can say that the uncertainty of the firm is more important to explain the company's investment level than the total uncertainty, so the approach that explains the effect of uncertainty on the level of investment is the Real Options Theory (ROT).Faced with this evidence, they rejected the hypothesis 1 , that market uncertainty has a negative effect on the level of investment, and the hypothesis 2 (a), that the idiosyncratic uncertainty has a negative effect on the level of investment.Furthermore, according to the results, it was found that, in Brazilian market, smaller firms are more sensitive to uncertainties and changes in the business environment than the bigger firms.As for competitiveness, it was identified that the most competitive companies are more sensitive to uncertainty than the less competitive.Moreover, the study sample was restricted to the period of full IFRS, considering the changes in accounting practices that changed the way of measurement of some explanatory variables.Therefore, after this restriction, it was found that there was no variation of the effect of total market, sector, and specific of firm uncertainties on the level of investment.In this sense, based on the results, it was observed that the uncertainty has a negative effect on the level of business investment, particularly the specific uncertainty of the firm, as predicts the TOR.Therefore, administrators should consider it in the decision-making process. It is noteworthy that these results may encourage the establishment of policies for viability analysis of new investment projects. Finally, the conclusions obtained in this dissertation should be restricted to the sample used.
\end{abstract}

Keywords: Investment. Uncertainty. Real Options Theory. 


\section{LISTA DE QUADROS}

Quadro 1 - Relação entre as variáveis de opções financeiras e de opções reais

Quadro 2 - Resumo dos principais trabalhos que analisaram o efeito da incerteza sobre o nível de investimento

Quadro 3 - Resumo das medidas de incerteza utilizadas no estudo

Quadro 4 - Sinais esperados dos coeficientes dos parâmetros da Equação 4 


\section{LISTA DE TABELAS}

Tabela 1 - Resultados dos testes de identificação dos modelos de painel 46

Tabela 2 - Testes para vesrificar endogeneidade $\quad 46$

Tabela 3 - Amostra do estudo (2008-2014) 50

Tabela 4 - Estatística descritiva (2008-2014) 51

Tabela 5 - Matriz de correlação de Pearson(2008-2014) 52

Tabela 6 - Testes de multicolinearidade (2008-2014) 53

Tabela 7 - Efeito da incerteza sobre o nível de investimento das empresas (2008-2014) 54

Tabela 8 - Efeito da incerteza sobre o nível de investimento para firmas maiores e menores (2008-2014)

Tabela 9 - Efeito da incerteza sobre o nível de inestimento para firmas mais competitivas e $\begin{array}{ll}\text { menos competitivas (2008-2014) } & 60\end{array}$

Tabela 10 - Efeito da incerteza sobre o nível de inestimento para o período de full IFRS 63

Tabela 11 - Resultado dos testes de verificação de endogeneidade para a proxy alternativa de incerteza

Tabela 12 - Efeito da incerteza sobre o nível de investimento para o período de 2008-2014 e de full IFRS com proxy alternativa para incerteza 


\section{LISTA DE ABREVIATURAS E SIGLAS}

\begin{tabular}{|c|c|}
\hline AIC & Critério de Informação de Akaike \\
\hline $\mathrm{BIC}$ & Critério de Informação Bayesiano \\
\hline BM\&FBovespa & Bolsa de Valores, Mercados e Futuros de São Paulo \\
\hline CAPM & Capital Asset Pricing Model \\
\hline $\mathrm{CFO}$ & Diretor Financeiro \\
\hline Ebitda & Lucros antes de Impostos, Taxas, Depreciação e Amortização \\
\hline END & Endividamento \\
\hline EUA & Estados Unidos da América \\
\hline FCD & Fluxo de Caixa Descontado \\
\hline FM-OLS & FullyModified OLS \\
\hline G7 & Grupo dos Sete \\
\hline GARCH & Generalized Autoregressive Heteroskedastic \\
\hline GMM & Método dos Momentos Generalizados \\
\hline HHI & Índice de Herfindahl-Hirschman \\
\hline HME & Hipótese do Mercado Eficiente \\
\hline Ibovespa & Índice da Carteira Teórica da Bovespa \\
\hline IEE & Índice Energia Elétrica \\
\hline IFRS & International Financial Reporting Standards \\
\hline INDX & Índice Industrial \\
\hline ICON & Índice Consumo \\
\hline IMOB & Índice Imobiliário \\
\hline IFNC & Índice Financeiro \\
\hline IMAT & Índice Materiais Básicos \\
\hline LM & Lagrange Multiplie \\
\hline LANT & Logaritmo Natural do Ativo Total \\
\hline UTIL & Índice Utilidade Pública \\
\hline MQ2E & Mínimos Quadrados em Dois Estágios \\
\hline MQO & Mínimos Quadrados Ordinários \\
\hline $\mathrm{ON}$ & Ordinárias Nominativas \\
\hline P\&D & Pesquisa e Desenvolvimento \\
\hline PIB & Produto Interno Bruto \\
\hline PMG & Pooled Mean Group \\
\hline PN & Preferências Nominativas \\
\hline POT & PeckingOrder Theory \\
\hline RGI & Recursos Gerados Internamente \\
\hline $\mathrm{RMC}$ & Rentabilidade Marginal de Capital \\
\hline VPL & Valor Presente Líquido \\
\hline TIR & Taxa Interna de Retorno \\
\hline TOR & Teoria das Opções Reais \\
\hline UE & União Europeia \\
\hline VIF & Fator de Inflação da Variável \\
\hline
\end{tabular}


SUMÁRIO

1 INTRODUÇÃO 16

1.1 CONTEXTUALIZAÇÃO E PROBLEMA DE PESQUISA 16

1.2 OBJETIVOS 19

1.2.1 Objetivo geral 19

1.2.2 Objetivos específicos 19

$\begin{array}{lll}1.3 & 19\end{array}$

1.4 ESTRUTURA DA DISSERTAÇÃO 21

2 REVISÃO DA LITERATURA 22

$2.1 \quad$ DECISÕES DE INVESTIMENTO 22

2.2 TEORIA DAS OPÇÕES REAIS 25

2.3 EVIDÊNCIAS EMPÍRICAS 28

$3 \quad$ PROCEDIMENTOS METODOLÓGICOS 38

3.1 POPULAÇÃO E AMOSTRA DO ESTUDO 38

3.2 MENSURAÇÃO DA INCERTEZA 38

3.2.1 Calculando índice setorial 4

3.3 DESCRIÇÃO DO MODELO ECONOMÉTRICO 42

3.4 DESCRIÇÃO DAS VARIÁVEIS

4 ANÁLISE DOS DADOS

4.1 ESTATÍSTICA DESCRITIVA 50

4.2 INCERTEZA E INVESTIMENTO

4.3 ANÁLISE DE ROBUSTEZ

4.3.1 Tamanho da empresa

4.3.2 Efeito da competitividade

4.3.3 Quebra estrutural - full IFRS

$\begin{array}{lll}\text { 4.3.4 Medida alternativa de incerteza } & 64\end{array}$

$5 \quad$ CONCLUSÃO $\quad 68$

$\begin{array}{ll}\text { REFERENCIAS } & \mathbf{7 1}\end{array}$ 


\section{INTRODUÇÃO}

Esta seção tem como objetivo apresentar uma contextualização do tema abordado na dissertação, o problema de pesquisa, os objetivos gerais e específicos, a justificativa e estrutura deste estudo.

\subsection{CONTEXTUALIZAÇÃO E PROBLEMA DE PESQUISA}

As constantes mudanças do ambiente empresarial, devido ao crescimento acelerado das economias, e as inovações tecnológicas promoveram um aumento da competição e da incerteza no espaço corporativo, tornando a flexibilidade gerencialessencial para o processo de tomada de decisão dos administradores (XU, WANG; XIN, 2010; KELLONG, 2014).

Conforme Trigeorgis (1996) e Minardi (2000), a flexibilidade gerencial refere-se ao fato de que, com o passar do tempo, os investidores podem alterar suas decisões de investimento,àmedida que obtêmnovas informações sobre o projeto, visando à maximização dos retornos e à redução das perdas. Adicionalmente, Dixit e Pindick (1994) e Bekoe e Adom (2013) afirmam que, em um ambiente de incerteza, as decisões de investimento devem levar em consideração a interação entre três características: (a) irreversibilidade parcial ou completa; (b) incerteza quanto aos retornos gerados pelo projeto; e (c) timming quanto ao momento ideal da decisão do investimento(flexibilidade gerencial).

No entanto, os métodos tradicionais de análise de investimento negligenciam a interação dessas três características, considerando que os investimentos são do tipo "agora ou nunca" e que os gestores se utilizam de estratégias passivas para administração dos seus projetos(LUEHRMAN,1998; MINARDI, 2000; BEKOE; ADOM, 2013).Nesse sentido, dentre os muitos métodos que foram criados para resolver as falhas dos modelos tradicionais, destaca-se a Teoria das Opções Reais (TOR) como o mais promissor (DIXIT; PINDYCK, 1994; MINARDI, 2000; BULAN, 2005; SANTOS; PAMPLONA, 2005).

A TORé uma metodologia de análise de investimentos reais, análogaàs opções de compra do mercado financeiro, que permite ao administrador valorar as diversas opções existentes em qualquer projeto de investimento - como as de adiar, contrair, abandonar ou efetuar qualquer alteração no projeto, nos diversos estágios por ele assumidos, dentro do seu período de duração (TRIGEORGIS, 1996).

De acordo como estudo de Graham e Harvey (2001) e Truong, Partington e Peat (2008), sobre as práticas de finanças corporativas mais utilizadas, verificou-se que $26,59 \%$ e 
$32 \%$ dos diretores financeiros (CFOs) e empresas, respectivamente,fazem uso, sempre ou quase sempre, da TOR para análise de investimento.Ademais, Trigeorgis (1996) endossa que, mesmo indiretamente, os gestores utilizam-se da TOR quando,intuitivamente, optam por postergar um investimento, devido às incertezas do ambiente corporativo.Dessa forma, podese afirmar que aTOR tem sido uma prática bastante utilizada para análise de investimentos em ativos reais (direta ou indiretamente).

Nessa ótica, diversos autores (DIXIT; PINDYCK, 1994; TRIGEORGIS, 1996; BULAN, 2001,2005; BULAN; MAYER; SOMERVILLE, 2009; TRAN, 2014) têm defendido a utilização da TOR para análise de investimentos,uma vez que, devido à irreversibilidade, à incerteza e ao timming (flexibilidade gerencial), a capacidade de adiar um investimento tornase valiosa, tendo em vista que o investidor poderá aguardar a redução da incerteza antes de decidir fazer o investimento irreversível, a fim de evitar potencializar grandes perdas, renunciando ao investimento completamente quando o resultado for desfavorável.

Dessa forma, tem-se quequanto maior for aincerteza em relação aos fluxos de caixa futuros esperados de um investimento, mais valiosa é a opção de adiar o projeto, reduzindo o incentivo para o exercício da opção hoje. Sendo assim, pode-se afirmar que a incerteza tem efeito negativo sobre investimento (BULAN, 2001, 2005; BYRNE; DAVIS, 2005;ABDULHAQUE; SHAOPING, 2008; XU, WANG, XIN, 2010; KELLONG, 2014; TRAN, 2014; KHALEGHI;PEYAMBARPEY; AMERI, 2015).

Entretanto, a TORnão é o único modelo a prever essa relação negativa entre incerteza einvestimento. Ateoria tradicional afirma que essa relação também pode serexplicada pelo risco sistemático (calculado pelo modelo Capital Asset PricingModel(CAPM), por exemplo), uma vez que afeta o custo de capital das empresas, aplicado nos modelos tradicionais de fluxo de caixa descontado (FCD) para análise de investimento (BULAN, 2005).Uma taxa de desconto de capital mais alta resulta em um menor valor presente líquido (VPL) dos projetos de investimento e, portanto, menos investimentos serão feitos (PANOUSI; PAPANIKOLAOU, 2012).

Segundo Bulan, Mayer e Somerville (2009), as pesquisas empíricas têm sofrido para diferenciar o efeito da TORe da teoria tradicional (modelos tradicionais de FCD em que a taxa de desconto depende do risco) nas decisões de investimento, uma vez que ambas defendem um efeito negativo da incerteza sobre o investimento. Entretanto, Bulan (2001, 2005) e Bulan, Mayer e Somerville (2009)endossam que,diferentemente do risco sistemático (mercado), que está para reduzir o investimento em uma variedade de modelos, inclusive na TOR,o risco da 
indústria ou incerteza da indústria sobre o investimento é exclusivo para o modelo de opções reais, distinguindo, portanto, o comportamento das opções reais dos modelos tradicionais.

Ressalta-se que, para a TOR,é a incerteza total, isto é, a de mercado, a idiossincrática e a específica da firma, que importa para as decisões de investimento, enquanto que para a teoria tradicional, o único risco relevante para a empresa é o de mercado, uma vez que as empresas possuem investimentos diversificados. Logo, o risco não sistemático não deve ter efeito sobre a valorização de um projeto (BULAN, 2001, 2005). Neste trabalho, os termos risco e incerteza são considerados idênticos, uma vez que a literatura sobre opções reais refere-se à volatilidade da demanda variável subjacente, tal como uma medida de incerteza (BULAN, 2001).

Nesse sentido, realizaram-se inúmeros estudos (BYRNE; DAVIS, 2005; BULAN, 2005; BLOOM; BOND; VAN REENEN, 2007; ABDUL-HAQUE; SHAOPING, 2008; BAUM; CAGLAYAN; TALAVERA, 2008, 2010; PEREIRA, 2008; BULAN; MAYER; SOMERVILLE, 2009; SÂMAN, 2010; XU; WANG; XIN, 2010; PANOUSI; PAPANIKOLAOU, 2012;BEKOE; ADOM, 2013; KELLOG, 2014;TRAN, 2014)visando verificar o efeito da incerteza sobre o nível de investimentos. A maioria deles evidenciou um efeito negativo da incerteza sobre o investimento, contudo, poucos demonstraram se essa evidência era devido ao comportamento das opções reais ou de teorias alternativas.

Bulan (2005) encontrou, ao segregar a incerteza total em seus componentes de risco, evidências substanciais em favor da TOR. Especificamente, observou que as incertezas idiossincrática (da indústria) e específica da firma têm um efeito negativo sobre o investimento. Em contrapartida, contrariando o esperado, o risco de mercado apresentou uma relação positiva com o investimento. Tran (2014) evidenciou um efeito negativo das incertezas macroeconômica e específica da firma sobre os investimentos australianos, destacando que a incerteza específica da firma é mais importante para explicar os investimentos de uma empresa do que a incerteza macroeconômica, fato que corrobora a TOR.

Consoante a esses estudos, Xu, Wang e Xin (2010) pesquisaram o efeito da incerteza nas decisões de investimento das empresas chinesas de controle privado e governamental, e verificaram uma relação negativa entre a incerteza e o investimento, para empresas privadas, enquanto que,para as empresas de controle do governo, esse efeito foi positivo. Esse fato pode ser justificado, segundo os autores, pela interferência do Estado e fraca governança corporativa, o que distorce a tomada de decisão dos investidores. 
Na literatura nacional, poucos estudos (SEABRA, 1996; PEREIRA, 2008) analisaram o efeito da incerteza sobre o investimento, e nenhum deles buscou justificar seus resultados, partindo da ótica das opções reais. Nesse sentido, surge o interesse de estudar o efeito da incerteza sobre as decisões de investimentos no mercado de ações brasileiro, sob a ótica da TOR. Diante do exposto, tem-se a seguinte questão de pesquisa: Qual o efeito da incerteza sobre o nível de investimento das empresas de capital aberto listadas na Bolsa de Valores, Mercadorias e Futuros de São Paulo (BM\&FBovespa)?

\subsection{OBJETIVOS}

\subsubsection{Objetivo geral}

O objetivo geral deste estudo é analisar o efeito da incerteza sobre o nível de investimento das empresas de capital aberto listadas na BM\&FBovespa.

\subsubsection{Objetivos específicos}

Para alcançar o objetivo geral, definiram-se os seguintes objetivos específicos:

a) Investigar o poder explicativo das variáveis de incerteza para o nível de investimento das organizações;

b) Verificar se a TOR explica o efeito da incerteza sobre o nível de investimento das firmas;

c) Identificar se o tamanho da empresa interfere no efeito da incerteza sobre o nível de investimento; e

d) Averiguar se a competitividade interfere no efeito da incerteza sobre o nível de investimento das organizações.

\subsection{JUSTIFICATIVA}

A compreensão do efeito da incerteza sobre o nível de investimento das organizações é de suma importância para a tomada de decisões de investimento (BULAN, 2005; TRAN, 2014; ESCALARES; KOTTARIDI, 2014), principalmente quando os países estão passando 
por um período de crise na economia nacional, uma vez que eleva a incerteza quanto ao futuro dos projetos (ESCALARES; KOTTARIDI, 2014).

Nos últimos anos, três temáticas têm sido abordadas em estudos sobre $\mathrm{o}$ comportamento das decisões de investimento das empresas: (a) investimento e restrições financeiras; (b) investimento e sensibilidade às dívidas; e (c) relação entre incerteza e investimento com base na TOR (XU; WANG; XIN, 2010). As duas primeiras temáticas são bem documentadas na literatura, enquanto que o efeito da incerteza sobre o nível de investimento com base na TOR ainda é pouco documentada e apresenta resultados conflitantes (XU; WANG; XIN, 2010; BULAN, 2005). Aliadas a isso, somam-se as diferentes proxies para mensuração da incerteza, nos períodos estudados, assim como diversos métodos econométricos, que dificultam a comparação de resultados.

De acordo com Pereira (2008), Sâman (2010), Bekoe e Adom (2013) e Tran (2014), a maioria dos estudos a respeito do efeito da incerteza sobre o nível de investimento é desenvolvida no Reino Unido e Estados Unidos da América (EUA), e poucos autores têm se dedicado a pesquisar em países não anglo-saxônicos. Tran (2014) endossa que é necessário o desenvolvimento de pesquisas nessa área em outros países, uma vez que podem ser encontrados resultados diferentes que irão auxiliar o entendimento sobre a temática. Sendo assim, inspirado nos trabalhos de Bulan (2005), Bloom, Bond e Van Reenen (2007), Baum, Caglayan e Talavera (2008), Xu, Wang e Xin (2010) e Tran (2014), o presente estudo examinou o efeito da incerteza sobre o nível de investimentos das organizações, com o objetivo de verificar se a incerteza explica parte das variações do nível de investimento no mercado brasileiro.

Nesse sentido, a pesquisa contribuirá ao trazer o debate do efeito da incerteza sobre o nível de investimento sob a ótica das opções reais, sobretudo com dados de mercados emergentes. Ademais, destaca-se que pesquisas nessa área são bastante incipientes no Brasil, identificando-se apenas os estudos de Seabra (1996) e Pereira (2008). Contudo, esses trabalhos não fazem uma abordagem sob a ótica da TOR.

A TOR defende que as oportunidades de um determinado projeto de investimento deverão ser analisadas como um conjunto de opções reais.Sendo assim, em um ambiente de elevada incerteza, os administradores têm a opção de adiar um investimento (flexibilidade gerencial) em resposta ao comportamento do mercado. Portanto, pode-se afirmar que a incerteza do ambiente de negócios reduz o nível de investimento. Dessa forma, ao avaliar os projetos de investimentos, os gestores devem levar em consideração a incerteza do ambiente de negócios. 
Com a finalidade de ter uma visão mais detalhada do efeito da incerteza sobre o nível de investimento e comprovar que o efeito é devido a TOR, a incerteza total do ambiente de negócios foi decomposta em:(a) de mercado; (b) idiossincrática; e (c) específica da firma. Com isso, é possível verificar se o efeito da incerteza sobre o nível de investimento é, de fato, devido à TOR ou a teorias alternativas (teoria tradicional, por exemplo). Assim, os resultados encontrados nesta pesquisa poderão fomentar o estabelecimento de novas políticas corporativas que levem em consideração outros tipos de risco na avaliação de investimento. Adicionalmente, espera-se que, partindo dos resultados do presente estudo, os administradores e os demais usuários da informação, possam alocar seus recursos de maneira mais eficiente, visando à maximização dos seus recursos.

\subsection{ESTRUTURA DA DISSERTAÇÃO}

Esta dissertação está estruturada em cinco seções, incluindo esta introdução, que faz parte da primeira. A segunda seção apresenta uma breve discussão a respeito das decisões de investimento, a TOR e evidências empíricas sobre o efeito da incerteza sobre o nível de investimento. A terceira, por sua vez, descreve os dados e os procedimentos metodológicos utilizados. A quarta evidencia os resultados provenientes da investigação empírica. E, por último, a quinta seção apresenta a conclusão. 


\section{REVISÃO DA LITERATURA}

Esta seção tem como objetivoapresentar uma revisão da literatura sobre o assunto estudado, abordando aspectos das decisões de investimento e a TOR, bem como apresentar um breve levantamento de evidências empíricas que analisam o efeito da incerteza sobre o investimento.

\subsection{DECISÕES DE INVESTIMENTO}

Investimento decorre do ato de incorrer em custos imediatos na expectativa de fluxos de caixa futuros, visando à maximização da riqueza da empresa (DIXIT; PINDYCK, 1994). Para tanto, os investimentos podem ser financeiros ou em ativos reais. Os investimentos financeiros consistem em aquisições de ativos financeiros, tais como títulos de dívida pública e depósitos à ordem, enquanto os investimentos em ativos reais são aqueles relacionados com o desenvolvimento da atividade da empresa e não são negociados no mercado financeiro (SANTOS; PAMPLONA, 2005).

De acordo com Dixit e Pindyck (1994), a maioria das decisões de investimentos compartilha de três importantes características: (a) irreversibilidade parcial ou completa; (b) incerteza; e (c) timming. A irreversibilidade parcial ou completa refere-se ao fato que o custo inicial de um investimento é, pelo menos, parcialmente perdido (sunk cost), isto é, se o investimento não apresentar resultados favoráveis e/ou esperados, não existe a possibilidade de recuperar todo o capital que foi investido, ou ao menos a maior parte deste (CABALLERO; PINDYCK, 1996; SEABRA, 1996).

Bulan (2005) e Tran (2014) destacam que a irreversibilidade é mais acentuada quando o investimento é específico da firma ou da indústria que a empresa atua.Contudo, mesmo quando os investimentos não são específicos da firma ouda indústria,podem ser considerados parcialmente irreversíveis - caminhões, computadores e equipamentos de escritórios, por exemplo, podem ser vendidos a empresas de diferentes indústrias, porém, a valores inferiores ao custo de reposição, devido ao efeito da assimetria informacional entre o comprador e o vendedor (PINDYCK, 1991; SEABRA, 1996).

Nesse sentido, a irreversibilidade faz com que a opção de adiar um investimento tenha valor, porque, com exceção dos investimentos do tipo "agora ou nunca", o diferimento é reversível (MCDONALD; SIEGEL, 1986; DIXIT; PINDYCK, 1994; BYRNE, DAVIS, 2005; 
KELLOGG, 2014). Portanto, um investimento irreversível só será realizado quando a probabilidade de insucesso seja suficientemente baixa.

A incerteza nas decisões de investimento está diretamente relacionada à volatilidade dos fluxos de caixa futuros dos investimentos, tendo em vista a dificuldade para prever a remuneração dos projetos de investimentos em períodos futuros (PINDYCK, 1993; BYRNE; DAVIS, 2005). Conforme Dixit e Pindyck (1994), os investimentos podem ser impactados por dois tipos de incerteza: (a)econômica (macroeconômica); e (b) técnica. A incerteza macroeconômica refere-se aos movimentos aleatórios da economia, sendo exógena ao processo de decisão de uma firma. Já a incerteza técnicaestá relacionada às características do projeto que está sendo avaliado, sendo, assim, considerada endógena ao processo de decisão.

De acordo com Trigeorgis (1996), ao contrário da incerteza técnica, a econômica não pode ser diversificável, assim, quanto maior for a incerteza econômica, maior será o custo de oportunidade associado ao investimento imediato. Esse fato tem como consequência um aumento no tempo de espera para o momento ótimo de investir ou a exigência de um elevado benefício para justificar o investimento.

Por fim, tem-se otimming, que consiste na flexibilidade quanto ao timming de realização do investimento. A teoria neoclássica trata todos os projetos de investimento como do tipo "agora ou nunca", quando, na realidade, os administradores possuem flexibilidade gerencial quanto à decisão do momento do investimento. A flexibilidade gerencial, conforme Trigeorgis (1993), refere-se àpossibilidade de rever a estratégia inicial e alterar o plano de investimento, nas diferentes etapas de um projeto, conforme as novas condições econômicas.

Corroborando, Trigeorgis (1993), Dixit e Pindyck (1994) e Minardi (2000) afirmam que o timming está ligado à decisão de investir imediatamente ou adiar o projeto por um determinado período, a fim de reunir mais informações a respeito do investimento. Os autores destacam que essa liberdade, quanto ao momento da decisão, é essencial para a análise de projetos. Entretanto, é impossível se obter uma certeza absoluta quanto ao futuro dos investimentos, uma vez que há fatores que estão fora do controle do tomador de decisões.

Convém ressaltar que a incerteza e a flexibilidade quanto ao timming de investimento estão intimamente interligadas, uma vez que a incerteza impacta na possibilidade de adiamento de um investimento, isto é, à medida que a incerteza quanto ao fluxo de caixa futuro se eleva, aumenta-se a possibilidade de adiamento de um investimento.

Nesse contexto, as técnicas de orçamento de capital deverão levar em consideração a interação dessas três características (irreversibilidade, incerteza e timming)na análise de projetos de investimentos, para não comprometerem os objetivos da organização, que é a 
maximização da riqueza dos investidores, sobretudo em ambientes com incerteza (SANTOS; PAMPLONA, 2005). Conforme Graham e Harvey (2001)e Truong, Partington e Peat (2008),as técnicasde orçamento de capital mais utilizadaspara avaliação de investimentos é o VPL e a Taxa Interna de Retorno (TIR).

Ambas as técnicas se utilizam de uma taxa de desconto ajustada ao risco (custo de capital) para levar em consideração a incerteza/risco do ambiente corporativo. Para tanto, fazem uso, geralmente, do CAPM(GRAHAM. HARVEY, 2001; TRUONG; PARTINGTON; PEAT, 2008). Seu cálculo fundamenta-se em uma equação que demonstra a relação entre o risco e o retorno esperado (BULAN, MAYER; SOMERVILLE, 2009). Bulan (2001) argumenta que, embora o CAPM seja útil para a relação entre risco-retorno, o modelo, por si só, não é suficiente para aplicação de decisões ótimas de investimento, uma vez que só leva em consideração o risco sistemático, e não o risco totalou incerteza total de um investimento.

É importante destacar que, apesar de o VPL e a TIR serem os modelos mais comumente usados, tais técnicasapresentam aspectos questionáveis em sua metodologia, que negligenciam a irreversibilidade parcial ou completa ea flexibilidade quanto ao timming de realização do investimento (DIXIT; PINDYCK, 1994; TRIGEORGIS, 1996;BULAN, 2005; SANTOS; PAMPLONA, 2005; XU; WANG; XIN, 2010; BEKOE; ADOM, 2013).Adicionalmente, Brennan e Schwartz (1985)ressaltam que a análise tradicional também desconsidera o fato de que o risco do projeto pode ser afetado pela flexibilidade das decisões gerencias.

Especificamente, Trigeorgis (1996) e Luehrman (1998) argumentam que os modelos de FCD, tais como VPL e TIR, assumem que os gestores têm um comportamento passivo após a implementação dos projetos. No entanto, no ambiente coorporativo, à medida que vão chegando novas informações e a incerteza sobre o mercado vai se revelando, surge a possibilidade de a gerência redirecionar o planejamento/projeto, visando à maximização do retorno do investimento.

Assim, devido às falhas dos métodos tradicionais, acadêmicos e gestores têm buscado métodos mais sofisticados para avaliação de investimentos que sejam capazes de avaliar, corretamente, todas as fontes de valor de um investimento.Nesse sentido, tem-se a TOR (MINARDI, 2000; BULAN, 2005; SANTOS; PAMPLONA, 2005; XU; WANG; XIN, 2010), que será abordada na seção seguinte. 


\subsection{TEORIA DAS OPÇÕES REAIS}

ATOR é uma metodologia de avaliação de ativos reais oriunda de técnicas aplicadas ao mercado financeiro para análise de investimentos acionários e desenvolvida a partir dos artigos seminais de Black e Scholes (1973) e Merton (1973) para valoração de ativos financeiros.O termo "real options" foi cunhado pelo professor Stewart Myers (1977) em seu artigo intitulado Determinants of Corporate Borrowing, que caracterizou as oportunidades de investimentos das organizações em ativos reais como sendo análogas às opções de compra negociadas no mercado financeiro (AMRAM; KULATILAKA, 2000; MOEL; TUFANO, 2002; BULAN, 2001; XU; WANG; XIN, 2010).

Assim, conforme Dixit e Pindyck (1994) e Trigeorgis (1996), uma opção real é o direito, mas não a obrigação,de empreender uma ação (adiar, expandir, contrair ou abandonar) a custo predeterminado que se denomina preço de exercício, por um período preestabelecido (vida da opção). O valor da opção, ou também chamada oportunidade do investimento, é o valor econômico de um projeto, considerando a liberdade gerencial embutida nessa opção (PINDICK, 1991; DIXIT; PINDYCK, 1994; TRIGEORGIS, 1996; LUEHRMAN,1998).Nessa ótica, conformeDixit e Pindyck (1994), as opções reais representam a flexibilidade que um gerente tem para tomar decisões a respeito dos ativos reais, à medida que as informações e as incertezas dos fluxos de caixa vão se revelando, de forma que os retornos esperados sejam maximizados e/ou as perdas sejam minimizadas.

Adicionalmente, Amram e Kulatilaka (2000) endossam que as opções reais são uma forma de pensar que auxilia os gestores a formular suas estratégias de investimento, criando futuras oportunidades, a partir de investimentos de hoje.Dessa forma, as oportunidades de um determinado projeto de investimento deverão ser analisadas como um conjunto de opções reais, algumas inerentes aos projetos de investimento e outras constituídas mediante um custo maior de investimento (MYERS, 1977; TRIGEORGIS, 1993; MINARDI, 2000). Dentre as opções existentes, destacam-se: (a) opção de adiamento; (b) abandonar o investimento; (c) expandir o investimento; e (d) contrair os investimentos(TRIGEORGIS; 1993; MINARDI, 2000).

Além das opções destacadas anteriormente, há outros tipos de opções que resultam de combinações ou mudanças desses quatro tipos básicos, tal como a opção de mudar para outro projeto com melhores alternativas, opções de crescimento e opções compostas(MINARDI, 2000).Nesse contexto, observa-se que as opções reais permitem que o administrador tenha flexibilidade para adaptar suas futuras ações em resposta ao comportamento do mercado (incerteza).No entanto, assim como em opções financeiras, o ato de exercer a opção é 
irreversível, uma vez que o investidor jamais poderá recuperar a posição que detinha inicialmente, devido aos custos de ajustamento assimétricos.

Trigeorgis (1993) ressalta que, mesmo antes do surgimento da TOR, muitos gerentes corporativos já consideravam, intuitivamente, os elementos de flexibilidade gerencial em suas decisões de investimentos. Entretanto, além da flexibilidade gerencial, para o processo de tomada de decisão, Dixit e Pindyck (1994) argumentam a necessidade de analisar a incerteza do ambiente corporativo e a irreversibilidade dos investimentos, tendo em vista que a interação desses fatores é essencial para existência de uma opção real.

Corroborando, Trigeorgis (1993), Bulan (2005) e Tran (2014) afirmam que a capacidade de adiar as decisões de investimento (flexibilidade gerencial) é valiosa quando o investimento é irreversível e o futuro é incerto, uma vez que os gestores podem esperar a resolução da incerteza antes de decidir continuar com o investimento irreversível, de forma a evitar potencializar grandes perdas, renunciando completamente ao investimento quando o resultado for desfavorável.

Para Dixit e Pindyck (1994), o reconhecimento de uma oportunidade de investimento como uma opção de compra contribui para que os administradores entendam a função primordial da incerteza na definição do momento adequado (ideal) para a tomada de decisão do investimento, uma vez que a irreversibilidade da decisão de investir atribui um valor significativo à opção de adiar o projeto.

Nessa ótica, Minardi (2000) aborda que os métodos de análise de orçamento de capital que ignoram as opções reais subavaliaram o valor dos projetos de investimento de forma a ocasionar tomadas de decisões errôneas, isto é, rejeitar projetos que seriam estrategicamente interessantes para a organização ou aceitar processos mais rígidos em detrimento dos flexíveis. No entanto, ressalta-se que quando as flexibilidades gerenciais não são significativas, o VPL pode apresentar resultados satisfatórios para a análise de investimento, tendo em vista que o método de precificação de opções reais parte de uma expansão do método tradicional do VPL (TRIGEORGIS, 1993), conforme Equação 1:

$$
V P L_{\text {expandido }}=V P L_{\text {tradicional }}+\text { Valor }_{\text {Flexibilidade }} \text { Gerencial }
$$

Em que:

$V P L_{\text {expandido }}=$ valor do projeto considerando-se as oportunidades do investimento;

$V P L_{\text {tradicional }}=$ valor presente líquido tradicional; $\mathrm{e}$

Valor $_{\text {Flexibilidade Gerencial }}=$ valor das opções. 
Assim, observa-se, conforme dito anteriormente, que se não existir qualquer opção que conceda flexibilidade ao projeto, o valor do VPL expandido será igual ao valor do VPL tradicional. Dessa forma, o VPL tradicional apresentará resultados consistentes. Ademais, verifica-se que a existência de opções de flexibilidade altera o valor de um projeto. De acordo com Trigeorgis (1996), quanto maior for a probabilidade de receber uma nova informação (incerteza) sobre projeto e reagir sobre ela (flexibilidade), maior será o valor da opção do investimento (opções reais).

Dessa forma, para determinar o valor das opções reais (flexibilidade gerencial) de um determinado projeto, deve-se levar em consideração cinco variáveis básicas, conforme é realizado parao modelo de opções financeiras. No Quadro 1,apresenta-se a analogia entre as variáveis de uma opção financeira e das opções reais, para, em seguida, ser explicado como cada variável afeta o valor de uma opção real.

Quadro 1 - Relação entre as variáveis de opções financeiras e de opções reais
\begin{tabular}{|l|l|}
\hline \multicolumn{1}{|c|}{ Opção de compra ( call option) } & \multicolumn{1}{c|}{ Opções reais } \\
\hline Preço do ativo subjacente (preço da ação) & Valor presente do cash-flows esperado do projeto \\
\hline Preço de exercício da opção & Valor presente do investimento inicial \\
\hline Tempo para maturidade & Tempo até a oportunidade de investimento desaparecer \\
\hline Volatilidade da ação & Volatilidade do cash-flows do projeto \\
\hline Taxa livre de risco & Taxa de desconto \\
\hline
\end{tabular}

Fonte: Adaptado de Trigeorgis (1996) e Luehrman (1998).

No que concerne ao valor presente do fluxo de caixaesperado do projeto, tem-se que um aumento do valor presente do projeto aumentará o VPL tradicional e, portanto, o valor da opção real também aumentará. Quanto ao valor presente do investimento inicial, tem-se que um custo mais alto no investimento reduzirá o VPL tradicional, logo, reduzirá o valor da opção real. Em relação ao tempo até a oportunidade de o investimento desaparecer, tem-se que um maior prazo de expiração permitirá maior conhecimento das incertezas e, portanto, aumentará o valor da opção. Quanto à volatilidade do fluxo de caixado projeto (incerteza), considerando um ambiente com flexibilidade gerencial, pode-se afirmar que um aumento da incerteza aumentará o valor da opção real. Por fim, quanto à taxa de desconto, tem-se que um aumento da taxa de juros aumentará o valor da opção real, tendo em vista que diminuirá o valor do dinheiro no tempo e, portanto, a opção de adiar um investimento.

Conforme Trigeorgis (1996), apesar de a analogia entre as opções financeiras e reais permitir um avanço para análise do comportamento dos investimentos, ela não pode ser considerada perfeita, tendo em vista que as opções de investimento são mais complexas (MINARDI, 2000). Dentre as diferenças, o autor destaca que as opções de compra 
(financeiras) são um direito exclusivo de seu possuidor, enquanto que as opções de investimento são, na maioria dos casos, partilhadas com os diversos concorrentes. Essa situação pode levar o administrador a realizar antecipadamente um investimento, devido ao elevado grau de competitividade entre as empresas (PINDICK, 1991).

Ademais,Minardi (2000) lista uma série de diferenças entre as opções financeiras e reais, a saber: (a) as opções financeiras têm vida curta, geralmente menos de um ano para expiração, enquanto que as opções reais têm vida longa, sendo, em alguns casos, perpétuas; (b) os ativosobjetosde opções financeiras são comercializados em vários mercados e seus preços nunca serão negativos, já em opções reais, o ativo objeto (projeto) geralmente não é comercializado e seu valor pode ser negativo; (c) as opções financeiras possuem gerência passiva, enquanto que em opções reais a gerência é ativa;(d)o ativo-objeto das opções financeiras pode ser divisível, enquanto que em opções reais são indivisíveis; e (e) as opções financeiras têm um preço determinado e único, em opções reais o preço de exercício, valor do investimento no projeto, pode variar ao longo do tempo, em alguns casos de forma aleatória.

\subsection{EVIDÊNCIASEMPÍRICAS}

A literatura a respeito das decisões de investimentos tem evidenciado uma grande preocupação em relação ao efeito da incerteza no comportamento dos investimentos das empresas, principalmente na identificação de uma proxy de incerteza que afete o nível de investimento, tendo em vista que incerteza é uma medida de difícil mensuração (BULAN, 2005; BONTEMPI; GOLINELLI; PARIGI, 2010). Nesse sentido, esta seção apresenta um panorama do desenvolvimento de pesquisas que estudam o comportamento dos investimentos em condições de incerteza.

Pindyck (1993) analisou as decisões de investimentos irreversíveis, considerando que os projetos levam um determinado tempo para serem concluídos, baseando-se em dois tipos de incerteza:(a) técnica, incerteza sobre a dificuldade de conclusão de um projeto; e (b) de entrada de custos, incerteza sobre os preços dos insumos da construção civil. Para tanto,estimou os dados por meio de uma regressão em cross-section, concluindo que esses dois tipos de incerteza têm efeitos diferentes sobre as decisões de investimento, isto é, que a incerteza técnica torna o investimento mais atraente, enquanto que a incerteza da entrada de custo o torna menos atrativo.

Caballero e Pindyck (1996) pesquisaram os efeitos da incerteza agregada eidiossincráticasobre o investimento irreversível, everificaram uma relação positiva entre os 
dois tipos de incerteza e o ponto de disparo do investimento, ou seja, identificaram que as empresas aumentam o investimento quando estão diante de um cenário incerto. Leahy e Whited (1996), utilizando como proxy para incerteza a previsão do retorno das ações, encontraram que as organizações adiam ou reduzem o investimento diante de aumentos da incerteza.

Seabra (1996) verificou a relação entre incerteza cambial e investimento, partindo de um modelo com: (a) hipóteses neoclássicas; e (b) abordagem de investimento irreversível. O autor constatou uma relação positiva entre incerteza e investimento sob a ótica neoclássica e negativa na ótica de investimentos irreversível. Contudo, Seabra (1996) destaca que o modelo de investimento irreversível é mais realista, tendo em vista que, na prática, as despesas com capital são altamente irreversíveis.

Bell e Campa (1997), usando como medida de incerteza a volatilidade da taxa de câmbio, dos preços dos insumos e da demanda do produto, avaliaram a relação entre investimento e incerteza nas empresas de indústrias químicas dos EUA e da União Europeia (UE), constando que a volatilidade na taxa de câmbio tem um efeito negativo sobre a capacidade das empresas em adquirir novos equipamentos. Porém, a relação para a volatilidadedos preços dos insumos (inputprices) e da demanda do produto tiveram efeitos pequenos e insignificantes. Sarkar (1999),sob a ótica das opções reais, demonstrou que, em certas situações, um aumento da incerteza pode aumentar a probabilidade de investir e, assim, ter um impacto positivo sobre o investimento.

Minton e Schrand (1999) utilizaram como medida para incerteza a volatilidade do fluxo de caixa. Os resultados demonstraram que uma maior volatilidade do fluxo de caixa está associada a níveis médios mais baixos de investimento em despesa de capital, pesquisa e desenvolvimento (P\&D) e publicidade, sugerindo que as empresas não usam os mercados de capitais externos para cobrir integralmente os déficits de fluxo de caixa, renunciando permanentemente a investimentos. Portanto, os autores concluem que há uma relação negativa entre investimento e incerteza.

Moel e Tufano (2002) analisaram, sob a ótica das opções reais, os determinantes do tradeoff da decisão de fechar ou reabrir uma mina de ouro, e observaram que a volatilidade no preçode ourotem um efeito negativo e estatisticamente significativo sobre essas decisões.Byrne e Davis (2005) avaliaram o impacto de uma ampla gama de potenciais fontes de incerteza no nível de investimento das empresas em todo o Grupo dos Sete (G7), isto é, EUA, Canadá, Japão, Reino Unido, Alemanha, França e Itália. A incerteza foi medida tanto por variáveis financeiras (preço das ações, taxa de juros e de câmbio), quanto por variáveis 
macroeconômicas (inflação e produção industrial). Os resultados indicaram que apenas a medida de incerteza da taxa de câmbio é significativa para influenciar o investimento em todo G7,apresentandoum efeito negativo, conforme esperado pelos autores.

Bulan (2005),sob a ótica da TOR,investigou o efeito da incerteza total no comportamento dos investimentos de 2.901 empresas do setor manufatureiro dos EUA, durante o período de 1964 a 1999. Para tanto, utilizou como medida para incerteza total a volatilidade do retorno das ações, que foi decomposta em seus componentes de mercado, indústria e específicos da firma. Os resultados evidenciaram que o investimento tem uma relação negativa com as incertezas idiossincrática e específica, consistente com as opções reais, enquanto que a relação com a incerteza sistemática épositiva.

Bloom, Bond e Reenen (2007) utilizaram a mesma medida de incerteza do estudo de Leahy e Whited (1996), para analisar a dinâmica do comportamento do investimento em condições de incerteza de 672 organizações britânicas, no período de 1972 a 1991. Para estimação dos dados, utilizaram o Método dos Momentos Generalizados (GMM). Assim, os autores constataram que, com (parcial) irreversibilidade, elevados níveis de incerteza tendem a diminuir os níveis de investimento das empresas, uma vez que aumentam a opção real de adiar o investimento.

Abdul-Haque e Shaoping (2008), usando dados de empresas chinesas no período de 1994 a2005, investigaram o impacto da incerteza sobre o nível de investimento. Como proxy para incerteza,utilizarama volatilidade dos retornos diários das ações. Assim, controlando os investimentos de curto e de longo prazo, os autores descobriram uma relação positiva entre a incerteza e os investimentos de curto e longo prazo. No entanto, estudos posteriorescom dados chineses (XU; WANG; XIN, 2010), utilizando a mesma proxy para incerteza, encontraram resultados contrários aos dos autores.

Baum, Caglayan e Talavera (2008) investigaram essa relação nas empresas norteamericanas, no período de 1984 a 2003, utilizando-se de três medidas de incerteza: (a) própria (intrínseca), derivada do retorno das ações das empresas; (b) do mercado (extrínseca), impulsionada pelo retorno do índice S\&P500; e (c) relação entre incerteza intrínseca e extrínseca. Para captar o último efeito, os autores introduziram um termo de covariância (a medida de risco baseada no CAPM). Os resultados indicaram que a incerteza da firma medida pela volatilidade do retorno diário das ações, assim como a incerteza baseada na medida de risco do CAPM, tem um impacto negativo com as despesas de investimento, enquanto que a incerteza do mercado medida pelo índice do mercado de capitais (o índice S\&P 500) tem um 
efeito positivo, sugerindo que, dependendo da medida utilizada, a incerteza pode afetar positivamente ou negativamente o investimento.

Pereira (2008) decompôs o investimento em máquinas e imóveis, e examinou o impacto da incerteza econômica sobre cada um desses componentes. Para tanto, analisou 22 setores de industriais brasileiras, no período de 1966 a 1995. O autor utilizou quatro medidas como proxy para incerteza:(a) média de salários; (b) valor agregado da indústria; (c) inflação; e (d) taxa de juros, todas aplicando o modelo Generalized Autoregressive Heteroskedastic (GARCH). O procedimento de estimação contou com métodos de dados em painel e de variáveis instrumentais para resolver os problemas de inconsistência. Dessa forma, observou que a incerteza reduz ambos os tipos de investimento. Entretanto, o efeito parece ser mais intenso com máquinas, o que poderia ser uma consequência de um custo de reversibilidade mais alto.

Bulan, Mayer e Somerville (2009), baseando-se na TOR, examinaram o desenvolvimento de 1.214 projetos de condomínios em Vancouver entre o período de 1979 a 1998, com o objetivo de identificar se o grau de incerteza atrasa os investimentos. Como medidas de incerteza, utilizaram os retornos imobiliários e o CAPM, e calcularam mensalmente por GARCH os retornos imobiliários. Os resultados sugeriram que os construtores retardam o desenvolvimento do projeto durante os períodos de maior incerteza idiossincrática dos retornos imobiliários e quando a exposição ao risco de mercado é maior, tal como esperado. Além disso, os autores evidenciaram que a concorrência reduz significantemente o exercício da opção de adiar o investimento, corroborando a TOR.

Baum, Cagalyan e Talavera (2010), utilizando a mesma base de dados e proxies para incerteza do seu trabalho de 2008, investigaram a relação entre as decisões de investimento com o fluxo de caixa em condições de incerteza. Os resultados indicaram que o sinal do coeficiente de incerteza é negativo para a incerteza específica da firma, para a incerteza de mercado (o índice S\&P 500) e para a incerteza baseada na medida de risco do CAPM. Contudo, quando a incerteza foi associada ao fluxo de caixa, os resultados foram ambíguos.

Sâman (2010) analisou a relação entre incerteza macroeconômica e o total de investimento de empresas da Romênia, no período de 2000 a 2008. Como proxy para incerteza,o autor utilizou quatro medidas macroeconômicas baseadas na volatilidade dos preçose da taxa de câmbio, a partir do modelo GARCH de Bollerslev (1986). O modelo linear mostrou um impacto negativo significativo da incerteza no investimento, com exceção para a proxy de incertezamedida pela taxa de câmbio USD/RON. 
$\mathrm{Xu}$, Wang e Xin (2010), utilizando a metodologia do estudo de Bulan (2005),identificaram que para as empresas chinesas de controle privado a relação entre investimento e incerteza é negativa, enquanto que para as controladas pelo governo o efeito é positivo, demonstrando que, além da proxy utilizada para medir incerteza, o tipo de controle também pode influenciar o efeito da incerteza sobre o comportamento de investimento. Os autores justificam tais resultados endossando que as empresas controladas pelo governo tendem a aumentar seu nível de investimento em período de maior incerteza para estimular o crescimento econômico do país.

Panousi e Papanikolaou (2012) analisaram o efeito da incerteza nos investimentos das empresas, com enfoque no risco idiossincrático. Para tanto, utilizaram como medida de referência para a incerteza a volatilidade mensal do retorno das ações, que foi decomposta em componentes sistemáticos e críticos. Assim, por meio do métododos Mínimos Quadrados Ordinários (MQO), os autores chegaram à conclusão que há uma relação negativa robusta, e provavelmente causal, entre o risco idiossincrático e o investimento para as empresas de capital aberto dos EUA. Contudo, a relação negativa é mais forte quando os executivos possuem uma grande fração de ações da empresa.

Bekoe e Adom (2013) investigaram, empiricamente, a relação entre investimento privado e a incerteza macroeconômica, usando um conjunto de dados de Gana, no período de 1975 a 2008. Como medida de incerteza, os autores utilizaram cinco variáveis, a saber: (a) inflação; (b) preço relativo dos bens de capital; (c) crescimento da produção (medida pelo produto interno bruto (PIB)real); (d) taxa de câmbio real; e (e) termos de troca. Para cada uma dessas variáveis, o estudo aplicou dois métodos para estimar a incerteza: (a) o modelo GARCH; e (b) o modelo de regressão recursiva. Em seguida, para analisar o efeito da incerteza sobre o investimento, o estudo empregou o modelo neoclássico de comportamento do investimento de Jorgenson (1963). Os parâmetros foram estimados por FullyModified OLS (FM-OLS) e os resultados indicaram que, com exceção da variável taxa de câmbio real, as demais apresentaram uma relação negativa com o investimento, conforme esperado pelos autores.

Czarnitzki e Toole (2013) analisaram a influência da incerteza e da competitividade sobre o nível de investimento em $\mathrm{P} \& \mathrm{D}$, sob a ótica das opções reais. Para tanto, a amostra constituiu-se de 870 empresas alemãs,no período de 1995 a 2001. Como proxy para incerteza, foi utilizado o coeficiente de variação das vendas defasada. Os autores verificaram que a incerteza tem um efeito negativo sobre os investimentos em P\&D, no entanto, em ambientes mais competitivos, o efeito negativo é menos intenso. Além disso, os resultados mostraram 
que grandes empresas reagem menos à incerteza de mercado do que as pequenas empresas, corroborando o esperado.

Escaleras e Kottaridi (2014) examinaram empiricamente o efeito conjunto da incerteza macroeconômica, a instabilidade sócio-política e o investimento público sobre o nível de investimento privado, usando dados de 37 países em desenvolvimento,no período de 1970 a 2000.Como proxy para incerteza macroeconômica, os autores utilizaram a volatilidade da taxa de inflação e da taxa de câmbio real, destacando que essas medidas de incerteza são adequadas por afetar as decisões de investimento por meio do VPL do projeto. Para estimar a volatilidade implícita das medidas de incerteza, foi utilizado o modelo $\operatorname{GARCH}(1,1)$, enquanto que a equação geral da pesquisa foi estimada por MQO e GMM. Os resultados mostram que a incerteza macroeconômica, a instabilidade sociopolítica e o investimento público têm um impacto negativo e significativo sobre o investimento privado.

Ezzahid et al. (2014) examinaram a relação entre diferentes medidas de incerteza e o volume de investimento das empresas marroquinas durante o período de 1980 a 2010 . Como proxies para incerteza,os autores utilizaram o PIB e o grau de desenvolvimento da economia. Os principais resultadosforam que o efeito da incerteza sobre o investimento depende da proxy utilizada na modelo econométrico. Especificamente, os autores encontraram um efeito negativo para o PIB e um efeito positivo para a incerteza medida pelo grau de desenvolvimento da economia.

Kellogg (2014), baseando-se na TOR, estimou a relação entre investimento e mudança de incerteza, utilizando dados sobre a exploração de petróleo no Texas e da volatilidade esperada do preço futuro do petróleo. $\mathrm{O}$ autor encontrou que existe uma relação negativa entre o investimento e a incerteza. Contudo, os dados de volatilidade implícita derivada dos preços das opções de futuros produzem um melhor ajuste para o investimento do que medidas de volatilidade retrospectivas como GARCH.

Tran (2014) investigou as empresas australianas ao longo do período de 1987 a 2009 e identificou que a incerteza tem um forte efeito negativo sobre os investimentos dasfirmas. Como principalproxy para incerteza, o autor utilizou a volatilidade do retorno das ações. Especificamente, a incerteza foi classificada em dois tipos: (a) incerteza específica da firma; e (b) incerteza macroeconômica. Os resultados evidenciaram quea incerteza específica da empresa é mais importante para as decisões de investimentos do que a incerteza macroeconômica. Além disso, o autor destaca que o efeito da incerteza é relativamente mais forte sobre o investimento em comparações com os outros fatores incluídos na regressão ( $q$ de Tobin; rentabilidade, fluxo de caixa, alavancagem e vendas). 
Khaleghi, Peyambarpey e Ameri (2015) examinaram o efeito da incerteza da taxa de câmbio real sobre os investimentos privados. Para tanto, a amostra do estudo se constituiu de 430empresas iranianas, durante o período de 1964 a 2011. Como proxy para incerteza,foi utilizada a taxa de câmbio real. O modelo geral da pesquisa foi estimado, usando o método de MQO, e os resultados foram que a incerteza da taxa de câmbio real tem um efeito negativo e significativo estatisticamente sobre os investimentos privados.

O Quadro 2 resume as pesquisas apresentadas neste tópico, que analisaram o efeito da incerteza sobre o investimento, bem como o sinal encontrado dessa relação.

\section{Quadro 2 - Resumo dos principais trabalhos que analisaram o efeito da incerteza sobre} o nível de investimento

\begin{tabular}{|c|c|c|c|c|}
\hline $\begin{array}{c}\text { Investigações } \\
\text { empíricas }\end{array}$ & País* & Proxy para incerteza & $\begin{array}{c}\text { Método } \\
\text { econométrico }\end{array}$ & $\begin{array}{l}\text { Efeito da incerteza } \\
\text { sobre investimento }\end{array}$ \\
\hline Pindyck (1993) & EUA & Técnica e de entrada de custos & $\begin{array}{l}\text { Regressão em } \\
\text { cross-section }\end{array}$ & $\begin{array}{l}\text { Positivo e negativo, } \\
\text { conforme proxy para } \\
\text { incerteza utilizada. }\end{array}$ \\
\hline $\begin{array}{c}\text { Caballero e } \\
\text { Pindyck (1996) }\end{array}$ & EUA & $\begin{array}{l}\text { Demanda agregada e unidades } \\
\text { produtivas }\end{array}$ & $\begin{array}{l}\text { Regressão em } \\
\text { cross-section }\end{array}$ & Positivo \\
\hline $\begin{array}{c}\text { Leahy e Whited } \\
\text { (1996) }\end{array}$ & EUA & $\begin{array}{c}\text { Volatilidade dos retornos das } \\
\text { ações }\end{array}$ & GMM & Negativo \\
\hline Seabra (1996) & BRA & Volatilidade da taxa de câmbio. & Abordagem teórica & Negativo \\
\hline $\begin{array}{l}\text { Bell e Campa } \\
\quad(1997)\end{array}$ & $\begin{array}{l}\text { EUA } \\
\text { e UE }\end{array}$ & $\begin{array}{c}\text { Volatilidade: das taxas de câmbio, } \\
\text { dos preços dos insumos e a } \\
\text { demanda do produto }\end{array}$ & Regressão truncada & Negativo \\
\hline Sarkar (1999) & EUA & Volatilidade dos lucros & MQO & Positivo \\
\hline $\begin{array}{l}\text { Minton e Schrand } \\
\text { (1999) }\end{array}$ & EUA & Volatilidade do fluxo de caixa & MQO & Negativo \\
\hline $\begin{array}{l}\text { Moel e Tufano } \\
\text { (2002) }\end{array}$ & EUA & Volatilidade do preço do ouro & MQO & Negativo \\
\hline $\begin{array}{l}\text { Byrne e Davis } \\
\quad(2005)\end{array}$ & G7 & $\begin{array}{l}\text { Variáveis financeiras (preço da } \\
\text { ação, taxa de câmbio e juros) e } \\
\text { variáveis macroeconômicas } \\
\text { (inflação e produção industrial) }\end{array}$ & $\begin{array}{l}\text { Pooled mean group } \\
\text { (PMG) }\end{array}$ & Negativo \\
\hline Bulan (2005) & EUA & $\begin{array}{l}\text { Volatilidade dos retornos das } \\
\text { ações }\end{array}$ & MQ2E & $\begin{array}{l}\text { Positivo e negativo, } \\
\text { segundo o tipo de } \\
\text { incerteza. }\end{array}$ \\
\hline $\begin{array}{l}\text { Bloom, Bond e } \\
\text { Reenen (2007) }\end{array}$ & GBR & $\begin{array}{l}\text { Volatilidade dos retornos das } \\
\text { ações }\end{array}$ & GMM & Negativo \\
\hline $\begin{array}{l}\text { Abdul-Haque e } \\
\text { Shaoping (2008) }\end{array}$ & $\mathrm{CHN}$ & $\begin{array}{l}\text { Volatilidade dos retornos das } \\
\text { ações }\end{array}$ & MQO e GMM & Positivo \\
\hline $\begin{array}{l}\text { Baum, Caglayan } \\
\text { e Talavera (2008) }\end{array}$ & EUA & $\begin{array}{l}\text { Volatilidade dos retornos das } \\
\text { ações }\end{array}$ & GMM & $\begin{array}{l}\text { Negativo e positivo, } \\
\text { segundo o tipo de } \\
\text { incerteza }\end{array}$ \\
\hline Pereira (2008) & BRA & $\begin{array}{l}\text { Volatilidade: media de salários, } \\
\text { valor agregado da indústria, } \\
\text { inflação e taxa de juros } \\
\end{array}$ & GMM & Negativo \\
\hline $\begin{array}{c}\text { Bulam, Mayers e } \\
\text { Somerville (2009) }\end{array}$ & $\mathrm{CA}$ & $\begin{array}{c}\text { Volatilidade dos retornos } \\
\text { imobiliários }\end{array}$ & MQO & Negativo \\
\hline $\begin{array}{c}\text { Baum, Cagalyan } \\
\text { e Talavera (2010) }\end{array}$ & EUA & $\begin{array}{l}\text { Volatilidade dos retornos das } \\
\text { ações }\end{array}$ & GMM & Negativo \\
\hline Sâman (2010) & RO & $\begin{array}{l}\text { Volatilidade dos preços e da } \\
\text { taxa de cambio. }\end{array}$ & GMM) & $\begin{array}{l}\text { Negativo e positivo, } \\
\text { conforme proxy para } \\
\text { incerteza }\end{array}$ \\
\hline
\end{tabular}


Quadro 2 -Resumo dos principais trabalhos que analisaram o efeito da incerteza sobre o nível de investimento

\begin{tabular}{|c|c|c|c|c|}
\hline $\begin{array}{c}\text { Investigações } \\
\text { empíricas }\end{array}$ & País* & Proxy para incerteza & $\begin{array}{c}\text { Método } \\
\text { econométrico }\end{array}$ & $\begin{array}{l}\text { Efeito da incerteza } \\
\text { sobre investimento }\end{array}$ \\
\hline $\begin{array}{l}\mathrm{Xu}, \mathrm{Wang} \text { e Xin } \\
(2010)\end{array}$ & $\mathrm{CHN}$ & $\begin{array}{l}\text { Volatilidade dos retornos das } \\
\text { ações }\end{array}$ & MQ2E & $\begin{array}{l}\text { Negativo e positivo, } \\
\text { dependendo do tipo de } \\
\text { controle (privado ou do } \\
\text { governo) }\end{array}$ \\
\hline $\begin{array}{c}\text { Panousi e } \\
\text { Papanikolaou } \\
(2012)\end{array}$ & EUA & $\begin{array}{l}\text { Volatilidade dos retornos das } \\
\text { ações }\end{array}$ & MQO & Negativo \\
\hline $\begin{array}{l}\text { Bekoe e Adom } \\
\quad \text { (2013) }\end{array}$ & ZAF & $\begin{array}{l}\text { Volatilidade: a inflação; o } \\
\text { preço relativo dos bens de } \\
\text { capital; o crescimento da } \\
\text { produção; a taxa de câmbio } \\
\text { real; e os termos de troca }\end{array}$ & FM-OLS & $\begin{array}{l}\text { Negativo e positivo, } \\
\text { conforme proxy para } \\
\text { incerteza utilizada }\end{array}$ \\
\hline $\begin{array}{l}\text { Czarnitzki e } \\
\text { Toole (2013) }\end{array}$ & $\mathrm{DE}$ & $\begin{array}{l}\text { Volatilidade das vendas } \\
\text { defasadas }\end{array}$ & GMM & Negativo \\
\hline $\begin{array}{c}\text { Escaleras e } \\
\text { Kottaridi (2014) }\end{array}$ & DI & $\begin{array}{c}\text { Volatilidade da taxa de inflação } \\
\text { e da taxa de câmbio real }\end{array}$ & MQO e GMM & Negativo \\
\hline $\begin{array}{l}\text { Ezzahid et al } \\
\qquad(2014)\end{array}$ & MA & $\begin{array}{c}\text { Volatilidade do PIB e do grau } \\
\text { de desenvolvimento da } \\
\text { economia }\end{array}$ & MQO & $\begin{array}{l}\text { Negativo e positivo, } \\
\text { conforme proxy para } \\
\text { incerteza utilizada }\end{array}$ \\
\hline Kellog (2014) & EUA & $\begin{array}{l}\text { Volatilidade esperada do preço } \\
\text { futuro do petróleo }\end{array}$ & MQO & Negativo \\
\hline Tran (2014) & AUS & $\begin{array}{l}\text { Volatilidade dos retornos das } \\
\text { ações }\end{array}$ & MQO e GMM & Negativo \\
\hline $\begin{array}{c}\text { Khaleghi, } \\
\text { Peyambarpey, } \\
\text { Ameri (2015) }\end{array}$ & IR & $\begin{array}{l}\text { Volatilidade da taxa de câmbio } \\
\text { real }\end{array}$ & MQO & Negativo \\
\hline
\end{tabular}

* AUS: Austrália; BRA: Brasil; CA: Canadá; CHN: China; DE: Alemanha; DI: Diversos países; EUA: Estados Unidos da América; GBR: Reino Unido; IR: Irã; MA: Marrocos; RO: Romênia; UE: União Europeia; ZAF: África.

\subsection{HIPÓTESES DE PESQUISA}

As hipóteses da presente pesquisa foram construídas com base nas evidências empíricas citadas na seção anterior, que investigaram o efeito da incerteza sobre o nível de investimento das organizações. De acordo com o Quadro 2, a maioria dos estudos encontrou um efeito negativo da incerteza sobre o nível de investimento, isto é, que um aumento da incerteza reduz o nível de investimento das empresas. Duas abordagens norteiam a explicação dessa relação negativa: a teoria tradicional e a TOR (BULAN, 2001, 2005; BULAN; MAYER; SOMERVILLE, 2009).

A teoria tradicional defende que os administradores deixam de investir quando houver um aumento no risco sistemático, tendo em vista que ele eleva o custo de capital da empresa, aumentando, assim, a taxa de desconto utilizada para avaliar o VPL dos novos projetos de investimentos. Esse aumento na taxa de desconto resulta em menores VPLs dos projetos e, 
portanto, menos investimentos serão realizados, uma vez que a empresa terá menos capital disponível para novos investimentos(BULAN; MAYER; SOMERVILLE, 2009).

Partindo dessa abordagem tradicional, existe uma série de evidências do efeito da incerteza de mercado sobre o nível de investimento. Tran (2014), por exemplo, identificou que para o mercado australiano, o efeito do risco sistemático é negativo e significante estatisticamente. Para o mercado norte-americano, Baum, Caglayan e Talavera (2008) encontraram resultados semelhantes. Assim, baseando-se na teoria tradicional e nos estudos de Baum, Canglayan e Talavera (2008) e Tran (2014),estabelece-se a primeira hipótese de pesquisa:

- $\mathbf{H}_{1}$ - No mercado acionário brasileiro, existe um efeito negativo da incerteza de mercado sobre o nível de investimento das organizações.

Quanto à segunda abordagem, aTOR defende que a relação entre incerteza e investimento é negativa porque os investidores têm a opção de adiar um investimento diante de um elevado nível de incerteza, a fim de capturar mais informações a respeito do investimento antes de concretizá-lo (BULAN, 2005). De acordo com Seabra (1996), Bulan (2001, 2005) e Tran (2014), a opção de adiar um investimento é relevante porque a maioria das despesas de capital das firmas é irreversível (ou parcialmente irreversível), ou seja, o preço de capital de compra é inferior ao seu preço de revenda.

Destaca-se que para teoria tradicional, apenas o risco sistemático (a incerteza de mercado) é relevante para as organizações, enquanto que para TOR, não só o risco de mercado tem influência sobre o nível de investimento, mas sim o risco total (risco de mercado, risco idiossincrático e especifico da firma). Nesse sentido, baseando-se na TOR e nas evidências de Bulan (2005) e Xu, Wang e Xin (2010), que encontraram um efeito negativo da incerteza total sobre o nível de investimento, tem-se a segunda hipótese de pesquisa:

- $\mathbf{H}_{2}$ - No mercado acionário brasileiro, existe um efeito negativo da incerteza total sobre o nível de investimento das empresas.

Contudo, para verificar se o efeito da incerteza sobre o nível de investimento é, de fato, causado pela TOR, faz-se necessáriaa decomposição da incerteza total em seus componentes de risco de mercado, idiossincrático e específico da firma. Caso seja observado 
que as incertezas idiossincrática ou específica da firma tenham um efeito negativo e significativo sobre o nível de investimento, poder-se-á concluir que o efeito é causado pela TOR. Do contrário, haverá uma ambiguidade quanto à abordagem que explica a relação negativa entre a incerteza e o nível de investimento das organizações, uma vez que tanto a teoria tradicional como a TOR defendem que a incerteza de mercado tem impacto no nível de investimento.

Assim, conforme o exposto e partindo dos estudos de Bulan (2005) e Xu, Wang e Xin (2010), que analisaram o efeito das incertezas idiossincrática e específica da firma sobre o nível de investimento das empresas norte-americanas e chinesas, respectivamente, têm-se as seguintes hipóteses:

- $\mathbf{H}_{2 \mathbf{a}}$ - No mercado acionário brasileiro, existe um efeito negativo da incerteza idiossincrática sobre o investimento das organizações.

- $\mathbf{H}_{2 \mathbf{b}}$ - No mercado acionário brasileiro, existe um efeito negativo da incerteza específica da firma sobre o investimento das organizações. 


\section{PROCEDIMENTOS METODOLÓGICOS}

\subsection{AMOSTRA DO ESTUDO}

A amostra inicial analisada foiconstituída de todas asempresas com ações listadas na BM\&FBovespa, entre o período de $1^{\circ}$ de janeiro de 2008 a 31 de dezembro de 2014. Esse marco temporal foi escolhido por causa da disponibilidade de informações dos índices setoriais a partir do ano de 2008. Da referidaamostra, foram excluídas as seguintes empresas:

a) Financeiras e de seguro, devido a seu relativamente baixo nível de investimento em capital físico (TRAN, 2014). Além disso, de acordo com Fama e French (1992), as instituições financeiras apresentam um alto grau de alavancagem que pode afetar os resultados da pesquisa, uma vez que o nível de alavancagem não tem o mesmo significado para empresas financeiras e nãofinanceiras;

b) Que não apresentaram valor de mercado no dia 31 de dezembro de cada ano, pois esses valores são utilizados para computar o $q$ de Tobin $^{1}$;

c) Que tiverem menos de 125 observações de retorno durante o ano, restringindo a amostra a empresas que comercializam por, pelo menos, $50 \%$ dos pregões em um ano; e

d) Que não apresentaram os dados necessários para a pesquisa.

Destaca-se que todos os dados relativos a informações contábeis e de mercadoforamobtidos por meio do banco de dados do Economatica ${ }^{\circledR}$ e do sítio eletrônico da BM\&FBovespa.Especificamente, a classificação de setores das empresas foi feita de acordo com as informações da BM\&FBovespa.

\subsection{MENSURAÇÃO DA INCERTEZA}

De acordo com Leahy e Whited (1996), Bulan (2001, 2005), Bontempi, Golinelli e Parigi (2010) e Bekoe e Adom (2013), a obtenção de uma medida geral de incerteza que afeta as empresas não é uma tarefa simples. Na literatura, vários tipos de proxies têm sido utilizadas para medir a incerteza, tais como: taxa de câmbio, demanda agregada, unidades produtivas,

\footnotetext{
${ }^{1} \mathrm{Q}$ de Tobin refere-se à oportunidade de investimento, tal variável será utilizada na Equação 4 para analisar o efeito da incerteza sobre o nível de investimento.
} 
fluxo de caixa, preço da ação, inflação, retorno das ações,dentre outras (SEABRA, 1996;CABALERRO; PINDYCK, 1996; LEAHY, WHITED, 1996; BELL; CAMPA, 1997; MINTON;SCHRAND, 1999; BYRNE; DAVIS, 2005; BULAN, 2005; BLOOM; BOND; REENEN, 2007; ABDUL-HAQUE; SHAOPING, 2008; BAUM; CAGLAYAN; TALAVERA, 2008, 2010; XU; WANG; XIN, 2010; PANOUSI; PAPANIKOLAOU, 2012; TRAN, 2014).

Para este estudo, utilizou-se a volatilidade dos retornos das ações, uma vez que apresenta a vantagem de capturar, em uma única variável, a incerteza total que é relevante para empresa, facilitando a decomposição do risco em seus vários componentes (BULAN, 2001, 2005).Além disso, de acordo com Leahy e Whited (1996), Bulan (2005), Byrne e Davis (2005),Baum, Caglayan e Talavera (2008, 2010), Xu, Wang e Xin (2010)e Tran (2014), a volatilidade dos retornos das ações é uma medida adequada, pois reflete os fatores de incerteza macros e microeconômicos enfrentados pelas organizações, capturando as reações do mercado quanto às notícias de oportunidades de investimento e rentabilidade futura que são relevantes para as decisões de investimentos das empresas (Hipótese do Mercado Eficiente (HME)).

Sendo assim, avolatilidade do retorno das ações, ou seja, o desviopadrão dos retornos diários da empresafoi calculado conforme Equação 2:

$$
\sigma_{i \tau}=\sqrt{\frac{1}{t_{i}} \sum_{\tau=1}^{t_{i}}\left(r_{i \tau}-\bar{r}_{i t}\right)^{2}}
$$

Em que:

$\sigma_{i \tau}=$ desvio padrão do retorno diários da ação $i$ no dia $\tau$;

$\tau=1,2, \ldots, \mathrm{t}_{\mathrm{i}}$. $\mathrm{t}_{\mathrm{i}}$ é o número de dias de negociação no ano $t$;

$r_{i \tau}=$ retorno diário da empresa $i$ no dia $\tau ; \mathrm{e}$

$\bar{r}_{i t}=$ a média do retorno diário da empresa $i$ no anot .

Os retornos diários são utilizadosporque geram medidas de volatilidade anual sem sobreposição de dados de retorno e minimizam o viés de pequena amostra (BULAN, 2005). Para verificar se a TOR explica a relação negativa entre investimento e incerteza, a incerteza total foi decompostaem seus componentes agregados e específicos da firma. Para tanto,foi utilizado o modelo de dois índices apresentado na Equação 3, com base nos estudos de Bulan (2001, 2005) e Xu, Wang e Xin (2010). 


$$
R_{i \tau}=\alpha_{i t}+\beta_{i t} R_{M \tau}+\gamma_{i t} R_{I \tau}+\varepsilon_{i \tau}
$$

Em que:

$R_{i \tau}=$ é o retorno diário das ações da empresa $i$ no dia $\tau$;

$\tau=1,2, \ldots, t i . t i$ são os números de dias de negociação da empresa $i$ no ano $t$;

$\alpha_{i t}=$ intercepto da regressão;

$\beta_{i t}=$ é o beta da incerteza de mercado da empresa $i$ no ano $t$;

$R_{M \tau}=$ retorno diário da carteira índice de mercado-IBovespa;

$\gamma_{i t}=$ gama da incerteza do setor da empresa $i$ no ano $t$;

$R_{I \tau}=$ retorno diário da carteira índice do setor da empresa, que é ortogonal ao retorno do mercado; e

$\varepsilon_{i \tau}=\mathrm{o}$ termo de erro com ruído branco.

O modelo acima foi estimado utilizando MQO para cada empresa, em cada ano da amostra do estudo, isto é, foram estimadas 1.278 regressões para capturar os três tipos de incerteza da empresa. Nesse sentido, a incerteza do mercado foi mensurada pelo beta de mercado das empresas multiplicado pelo desvio padrão anualizado do retorno da carteira do índice de mercado $\left(\hat{\beta}_{i t} . \hat{\sigma}_{M t}\right)$. Similarmente, a incerteza idiossincrática, que é ortogonal com o movimento da incerteza do mercado, foi mensurada pelo gama do setor da empresa multiplicado pelo desvio padrão anualizado do retorno da carteira índice do setor $\left(\hat{\gamma}_{i t} . \hat{\sigma}_{I t}\right)$.

Quanto à incerteza específica da empresa $\left(\hat{\sigma}_{\varepsilon i \tau}\right)$, foi mensurada pelo desvio padrão anualizado dos resíduos resultantes da regressão da Equação 3. É importante ressaltar que a volatilidade anual do retorno do mercado $\left(\hat{\sigma}_{M t}\right)$ e a volatilidade do retorno da indústria $\left(\hat{\sigma}_{I t}\right)$ são ortogonais ao retorno total do mercado $\left(\hat{\sigma}_{i t}\right)$.Além disso, destaca-se que todas as medidas de volatilidade foram multiplicadas pela raiz quadrada de 252 (número de dias de negociação em um ano), com o objetivo de anualizá-las.

Para efeito de comparação, uma medida alternativa de decomposição da incerteza total é estimada com a restrição que $\gamma_{i t}=0$ na Equação 3, cenário análogo ao CAPM. De acordo com Bulan (2001,2005),nesse modelo alternativo, a incerteza agregada está relacionada inteiramente com as forças do mercado, enquanto que a incerteza específica da empresa é resultado do componente de retorno que é ortogonal a apenas os movimentos de mercado. 
Comparando-se os dois modelos, tem se que: no modelo de dois índices (Equação 3), os efeitos diretos do índice de mercado e do índice da indústria no retorno das ações das firmas são medidos por parâmetros separados; enquanto que no modelo de mercado (análogo ao CAPM), o efeito do índice da indústria está intrínseco no índice de mercado, isto é, o beta de mercado captura o efeito indireto do índice da indústria no retorno do patrimônio da empresa, uma vez que é canalizado por meio do índice de mercado.No Quadro 3, tem-se um resumo das medidas de incerteza utilizadas no estudo.

\begin{tabular}{|c|c|}
\hline Medidas de Incerteza & Descrição \\
\hline Incerteza Total (INC_Total) & Desvio padrão anualizado do retorno da ação. \\
\hline Incerteza de Mercado (INC_Merc (b)) & $\begin{array}{l}\text { Beta de mercado das empresas multiplicado pelo desvio } \\
\text { padrão anualizado do retorno da carteira do índice de mercado } \\
\left(\hat{\beta}_{i t} . \hat{\sigma}_{M t}\right) \text { calculado com base da restrição } \gamma_{i t}=0 \text { imposta na } \\
\text { Equação } 3 \text { (modelo de mercado). }\end{array}$ \\
\hline Incerteza Específica da Firma (INC_Esp (b)) & $\begin{array}{l}\text { Desvio padrão anualizado dos resíduos resultantes da } \\
\text { regressão da Equação } 3 \text { com a restrição de } \gamma_{i t}=0 \text { (modelo de } \\
\text { mercado). }\end{array}$ \\
\hline Incerteza de Mercado (INC_Merc (c)) & $\begin{array}{l}\text { Beta de mercado das empresas multiplicado pelo desvio } \\
\text { padrão anualizado do retorno da carteira do índice de mercado } \\
\left(\hat{\beta}_{i t} . \hat{\sigma}_{M t}\right) \text { calculado com base no modelo de dois índices, } \\
\text { Equação } 3 \text {. }\end{array}$ \\
\hline Incerteza do Setor (INC_Setor (c)) & $\begin{array}{l}\text { Gama do setor da empresa multiplicado pelo desvio padrão } \\
\text { anualizado do retorno da carteira índice do setor }\left(\hat{\gamma}_{i t} . \hat{\sigma}_{I t}\right) \text {, } \\
\text { calculado com base no modelo de dois índice, Equação } 3 .\end{array}$ \\
\hline Incerteza Específica da Firma (INC_Esp (c)) & $\begin{array}{l}\text { Desvio padrão anualizado dos resíduos resultantes da } \\
\text { regressão da Equação } 3 \text { (modelo de dois índices). }\end{array}$ \\
\hline
\end{tabular}

É importante destacar que toda medição da incerteza tem que ser voltada para o futuro, tendo em vista que deve refletir rentabilidade futura. As medidas tratadas nesta pesquisa são expost. Contudo, sob a hipótese de expectativas racionais, pode-se usar valores de volatilidade defasados como proxy para volatilidade esperada. Esse fato acrescenta um erro de expectativa racional para o termo de erro que é ortogonal às informações disponíveis no início de cada período de tempo (BULAN, 2005).

Ademais, Schwert (1989) e Abdul-Haque e Shaoping (2008) endossamque a volatilidade defasada é a variável mais importante para previsão do retorno das ações para o período subsequente, sendo assim, valores defasados podem ser considerados instrumentos válidos na estimação.

Por fim, ressalta-se que a proxy utilizada para medir a incerteza do mercado, neste estudo, é comumente referida na literatura de finanças como risco sistemático, uma vez que a volatilidade dos retornos de ativos é uma medida de grau de risco do ativo. Entretanto, a literatura de opções reais refere-se à volatilidade da demanda variável subjacente, tal como 
uma medida de incerteza. Nesse sentido, o risco e as incertezas podem ser considerados sinônimos (BULAN, 2001).

\subsubsection{Calculandoíndice setorial}

Para decomposição da incerteza total, conforme Equação 3, faz-se necessário informações sobre o retorno diário da carteira índice do setor da empresa $\left(R_{I \tau}\right)$. De acordo com informações do site da BM\&FBovespa, têm-se formado para o mercado brasileiro sete índices setoriais, a saber: (a) índice energiaelétrica (IEE); (b) índice industrial (INDX); (c) índice consumo (ICON);(d) índice imobiliário (IMOB); (e) índice financeiro (IFNC); (f) índice materiais básicos (IMAT); e (g) índice utilidade pública (UTIL).Os índices setoriais foram construídos com o objetivo de ser um indicador do desempenho médio das cotações dos ativos de maior negociabilidade e representatividade do setor.

Contudo, convém destacarque para os setores de Petróleo, Tecnologia e Telecomunicações, não há índices setoriais formados. Assim, para evitar a exclusão das empresas desses setores da amostra da pesquisa, uma vez que essa informação é essencial para a decomposição da incerteza total em seus componentes de risco (risco de mercado, risco do setor e risco específico da firma), optou-se pela construção do retorno diário da carteira dos referidos setores. Para tanto, foi construída uma carteira de retorno de mínima variância para cada ano do estudo, com base na metodologia de Markowitz.

Para a seleção das ações que compuseram a carteira dos setores, seguiu-se a metodologia da BM\&FBovespa para a construção dos demais índices setoriais. Sendo assim, inicialmente,foram selecionadas todas as empresas do setor. Posteriormente, foram excluídas aquelas quenão participaram de, pelo menos, $70 \%$ dos pregões durante o ano e queestavam em recuperação judicial. Ressalta-se que a empresa pode ter mais de uma ação participando da carteira.

$\mathrm{Na}$ formação da carteira de mínima variância, estabeleceu-se que cada ativo/ação teria participação mínima de $5 \%$ e máxima de $20 \%$. A definição de $20 \%$ como participação máxima foi estabelecida conforme metodologia da BM\&FBovespa. Por fim, calculou-se o retorno da carteira, ano a ano, setor a setor, baseando-se nos pesos estabelecidos pelo processo de formação de carteira de Markowitz.

\subsection{DESCRIÇÃO DO MODELO ECONOMÉTRICO}


O modelo adotado nesta pesquisa teve como base os trabalhos de Bulan (2001, 2005),Abdul-Haque e Shaoping (2008), Baum, Caglayan e Talavera (2008, 2010),Xu, Wang e Xin (2010) e Tran (2014). Assim, para mensurar o efeito da incerteza sobre o nível de investimento, utilizou-se a Equação 4:

$$
\begin{gathered}
\frac{I_{i t}}{K_{i t-1}}=\beta_{0}+\beta_{1} \text { QTobin }_{i t-1}+\beta_{2} R G I_{i t-1}+\beta_{3} R M C_{i t-1}+ \\
\beta_{4} E N D_{i t-1}+\beta_{5} I N C_{i t}+v_{i}+n_{i}+\xi_{t i}
\end{gathered}
$$

Em que:

A variável dependente do modelo será $\frac{I_{i t}}{K_{i t-1}} ; I_{i t}$ é o nível de investimento (as despesas de capital em propriedades, instalações e equipamentos, excluindo aquisições) da empresa $i$ no ano $t$; e $K_{i t-1}$ é o estoque de capital da empresa $i$ no tempo $t$-1.

QTobin $_{i t-1}=$ variável independente $q$ de Tobin para empresa $i$ no ano $t$-1;

$R G I_{i t}=$ variável independente recursos gerados internamente para empresa $i$ no ano $t$ 1 ;

$R M C_{i t-1}=$ variável independente rentabilidade marginal do capital para empresa $i$ no tempo $t-1$;

$E N D_{i t-1}=$ variável independente nível de alavancagem da empresa $i$ no tempo $t-1$;

$I N C_{i t}=$ variável independente incerteza, que é mensurada por diversas medidas, conforme explicado na subseção 3.2;

$v_{i}=$ variávelindependente dummy de setor, inserida na equação para controlar os efeitos fixos específicos de cada empresa em determinado setor. Os efeitos fixos específicos são fatores desconhecidos que podem variar de empresa para empresa e que podem alterar o nível de investimento das organizações, tais como a política de investimento que são adotadas pelas organizações;

$n_{i}=$ variável independente dummy de ano das empresas, inserida na estimação com objetivo de controlar efeitos macroeconômicos, como choques agregados que podem afetar as decisões de investimento das organizações;

$\xi_{i t}=$ resíduo da equação; e

$\beta_{1}, \beta_{2}, \beta_{3}, \beta_{4}$ e $\beta_{5}=$ parâmetros do modelo.

Espera-se que $\beta_{1}$ seja significativamente positivo, tendo em vista que quanto maior a oportunidade de investimento ( $q$ marginal), maior o estímulo para investir. Na Teoria do $q$ de Tobin, tem-se que o investimento deve ser uma função crescente da razão entre o valor de 
mercado da empresa e o custo de recompra de novos ativos fixos no mercado, que é capaz de indicar como novos investimentos afetarão o valor presente dos lucros das organizações. Essa razão é denominada de $q$ marginal, que representa a taxa de investimento da organização, ou seja, o $q$ marginal indica quanto, a cada unidade de valor investido, a empresa criará ou destruirá de valor (TOBIN, 1969).

Conforme Hayashi (1982), a relevância do $q$ está em mostrar a relação entre o valor investido e quanto o investimento passou a valer após ter sido transformado em bens e atividades produtivas. Assim, quando $q>1$, o mercado estará valorizando mais o capital do que o custo de reposição. Portanto, tem-se estímulo a investir. Entretanto, se $q<1$, a relação será inversa e o estímulo será inibido. Nesse sentido, o $q$ de Tobin representa a oportunidade de investimento da organização (TOBIN; BRAINARD, 1968).

Quanto ao $\beta_{2}$,espera-se que tenha um sinal positivo, uma vez que quanto maiores os recursos gerados internamente, maiores serão os recursos para novos investimentos. A PeckingOrder Theory (POT) aborda que há uma hierarquia de financiamento nas organizações, na qual primeiramente as empresas se financiam por recursos próprios, em seguida por recursos de terceiros e, em último caso, emitem novas ações (MYERS, 1984; MYERS; MAJLUF, 1984). Nesse sentido, devido aos problemas de agência (JENSEN; MECKLING, 1976) e às restrições financeiras, o nível de investimento da organização pode estar totalmente relacionado aos recursos gerados internamente. Portanto, quanto mais recursos gerados internamente, maior o nível de investimento das organizações.

De acordo com Bulan (2005), o excesso de recursos gerados internamente pode pressionar os administradores a investirem em qualquer projeto que tenha um VPL positivo. Nessa ótica, as empresas gerarão maiores recursos internos e, consequentemente, tendem a investir cada vez mais para não perderem oportunidades de investimentos futuros. Nesse sentido, fez-se necessário capturar a rentabilidade marginal de capital e espera-se uma relação positiva $\left(\beta_{3}\right)$, tendo em vista que quanto maior a rentabilidade, maior deverá ser o investimento.

Em relaçãoa $\beta_{4}$, espera-se um sinal significativamente negativo, uma vez que o excesso de dívida poderá inibir as oportunidades de captar recursos para investimento.Modigliani e Miller (1958) defendem que a estrutura de capital das organizações deveria ser irrelevante para a tomada de decisão. No entanto, conforme Myers (1984), as empresas mais alavancadas apresentam conflito de interesse entre os detentores de capital e os de dívida, o que provoca uma relação negativa entre os investimentos e a alavancagem, tendo 
em vista que os conflitos impedem que os gestores aceitem projetos que tenham VPL positivo na presença de altos níveis de endividamento.

Quanto ao parâmetro $\beta_{5}$, de acordo com a TOR, espera-se um sinal significativamente negativo, tendo em vista que quanto maior a incerteza, maior a opção de adiar um investimento e,consequentemente, menor será o nível de investimento das organizações. No Quadro 4, tem-se um resumo da relação esperada dos coeficientes dos parâmetros em relação à variável dependente.

Quadro 4 - Sinais esperados dos coeficientes dos parâmetros da Equação 4

\begin{tabular}{|c|c|c|c|}
\hline Variáveis & Sigla & $\begin{array}{c}\text { Sinal } \\
\text { esperado }\end{array}$ & Referência \\
\hline $\begin{array}{c}\text { Oportunidade de } \\
\text { crescimento }\end{array}$ & QTobin $_{i t-1}$ & $(+)$ & $\begin{array}{c}\text { Tobin (1969), Bulan (2005), Baum, Caglayan, Talavera, } \\
(2008) \text { e Xu, Wang e Xin (2010), Tran (2014). }\end{array}$ \\
\hline $\begin{array}{c}\text { Níveis de recursos } \\
\text { gerados internamente }\end{array}$ & $R G I_{i t-1}$ & $(+)$ & $\begin{array}{c}\text { Bulan (2005), Baum, Caglayan, Talavera, (2008) e Xu, } \\
\text { Wang e Xin (2010), Tran (2014) }\end{array}$ \\
\hline $\begin{array}{c}\text { Rentabilidade } \\
\text { marginal do capital }\end{array}$ & $R M C_{i t-1}$ & $(+)$ & $\begin{array}{c}\text { Bulan (2005), Baum, Caglayan, Talavera, (2008) e Xu, } \\
\text { Wang e Xin (2010), Tran (2014) }\end{array}$ \\
\hline Nível de alavancagem & $E N D_{i t-1}$ & $(-)$ & $\begin{array}{c}\text { Baum, Caglayan, Talavera, 2008 e Xu, Wang e Xin } \\
(2010), \text { Tran (2014) }\end{array}$ \\
\hline Incerteza & $I N C_{i t}$ & $(-)$ & Teoria das Opções Reais \\
\hline
\end{tabular}

Destaca-se que, conforme a subseção 3.2, a incerteza da empresa foi mensurada por diversas proxies, assim, para a estimação da Equação 4, as medidas de incerteza foram agrupadas em três modelos, conforme o estudo de Bulan (2005) e Xu, Wang e Xin (2010). No modelo (a), usa-se a volatilidade do retorno total das ações como medida para incerteza total da empresa, enquanto o modelo (b) decompõe a incerteza total em seus componentes de mercado e específico da firma, conforme a restrição $\gamma_{i t}=0$ imposta na Equação 3. O modelo (c) decompõe a incerteza total em três componentes: o de mercado, o da indústria e o específico da firma, conforme o modelo de dois índices da Equação 3.

Em relação ao método econométrico para este trabalho, optou-se por utilizar a técnica de dados em painel, que corresponde a um conjunto de dados em uma série temporal para cada membro do corte transversal do conjunto de dados, possuindo três abordagens: pooled, efeitos fixos e efeitos aleatórios (BROOKS, 2002). Para identificar o tipo de dados em painel mais adequado às observações, fez-se necessário a aplicação de três testes, a saber: (a) teste de Chow; (b) teste Lagrange Multiplie (LM) de Breush-Pagan; e (c) teste de Hauman. Na Tabela 1,são apresentados os resultados desses testes. 
Tabela 1- Resultados dostestes de identificação dos modelos de painel

\begin{tabular}{cccc}
\hline TESTES & $(\mathbf{a})$ & (b) & (c) \\
\hline Teste de Chow & 0,96 & 0,91 & 0,90 \\
& $(0,645)$ & $(0,807)$ & $(0,841)$ \\
TesteLM de Breusch-Pagan & 0,00 & 0,00 & 0,00 \\
& $(1,000)$ & $(1,000)$ & $(1,000)$ \\
\hline
\end{tabular}

Nota: Os valores que se encontram entre parênteses correspondem ao $p$-valor de cada teste específico.

Conforme se observa na Tabela 1, para todos os modelos, a hipótese nula do teste de Chow (pooled versus efeito fixo) não pode ser rejeitada, indicando que a estimação por pooled é mais adequada do que a de efeitos fixos. Concomitantemente, verifica-se que a hipótese nula do teste LM de Breush-Pagan (pooledversus efeito aleatório) também não pode ser rejeitada. Portanto, o modelo de painel mais adequado para a pesquisa é o painel do tipo pooled. Ressalta-se que, com base nos resultados dos testes de Chow e LM Breush-Pagan, não se faz necessária a aplicação do teste de Hausman.

No que concerne à definição do método para estimação dos parâmetros da Equação 4,verificou-se inicialmente se as medidas de incerteza utilizadas no estudo eram endógenas, uma vez que Bulan (2005) destacou que poderia haver uma provável endogeneidade para essas medidas. Assim, na Tabela 2,são apresentadas as estatísticas do teste deDurbin, teste F e o teste de Wooldridge, para os modelos (a), (b) e (c). Os instrumentos utilizados foram o $q$ de Tobin defasadoeas demais medidas de incerteza, conforme o estudo de Bulan (2005) e Xu, Wang e Xin (2010).

Tabela 2 - Testes para verificar endogeneidade

\begin{tabular}{lccc}
\multicolumn{1}{c}{ TESTES } & (a) & (b) & (c) \\
\hline Teste de Durbin & 1,219 & 3,323 & 5,170 \\
& $(0,270)$ & $(0,190)$ & $(0,160)$ \\
Teste F & 377,966 & 167,370 & 20,577 \\
& $(0,000)$ & $(0,000)$ & $(0,000)$ \\
Teste de Wooldridge & 1,636 & 0,416 & 0,259 \\
& $(0,651)$ & $(0,519)$ & $(0,610)$ \\
\hline
\end{tabular}

Nota: Os valores que se encontram entre parênteses correspondem ao $p$-valor de cada teste específico.

Com base na Tabela 2, verifica-se que,nos três modelos analisados, a hipótese nula de que as variáveis são exógenas não pode ser rejeitada, conforme teste de Durbin. Posteriormente, foi verificado se os instrumentos utilizados são válidos para testar a provável endogeneidade, isto é, se os instrumentos são correlacionados com a variável "supostamente" endógena e não correlacionado com o erro.Para tanto, aplicou-se o teste $\mathrm{F}$ e o teste de 
Wooldridge. Assim, observa-se que, para todos os modelos, os instrumentos são válidos e não correlacionados com o erro estrutural, de acordo com os testes $\mathrm{F}$ e de Wooldridge, respectivamente.

Nessa ótica, para estimar os parâmetros da regressão 4, para os três modelos ((a), (b) e (c)), foi utilizado o método de MQO com dados em painel do tipo pooled não balanceado, uma vez que a provável endogeneidade não foi confirmada. Destaca-se que os pressupostos do modelo foram analisados.

\subsection{DESCRIÇÃO DAS VARIÁVEIS}

O retorno diário das ações/indústria/mercado foi obtido conforme Equação 7:

$$
R_{i, t}=\ln \left(\frac{P_{i, t}}{P_{i, t-1}}\right)
$$

Em que:

$R_{i, t}=$ retorno diário da das ação/indústria/mercado $i$ no dia $t-1$.

$P_{i, t}=$ cotação nominal da ação/indústria/mercado $i$ no dia $t$, ajustadas aos proventos; e

$P_{i, t-1}=$ cotação nominal da ação/indústria/mercado $i$ no dia $t-1$, ajustadas aos proventos.

A volatilidade do mercado e do setor, ou seja, o desvio padrão do retorno da carteira índice do mercado e do índice do setor, foi calculadaconforme a Equação 8:

$$
\sigma_{i, t}=\sqrt{\frac{1}{t_{i}} \sum_{\tau=1}^{t_{i}}\left(r_{i \tau}-\bar{r}_{i t}\right)^{2}}
$$

Em que:

$\sigma_{i, t}=$ desvio padrão do retorno diário do índice do mercado ou do índice do setor $i$ no ano $t$

$\tau=1,2, \ldots, \mathrm{t}_{\mathrm{i}} \cdot \mathrm{t}_{\mathrm{i}}=\mathrm{o}$ número de dias de negociação no ano $t ;$

$r_{i \tau}=$ retorno diário do índice de mercado ou do índice do setor $i$ no dia $\tau$; e

$\bar{r}_{i t}=$ média do retorno diário do mercado ou do índice do setor $i$ no ano $t$.

A volatilidade específica da firma foi calculadade acordo com a Equação 9: 


$$
\sigma_{i, t}=\sqrt{\frac{1}{t_{i}} \sum_{\tau=1}^{t_{i}} \hat{\varepsilon}_{i \tau}^{2}}
$$

Como proxy paraa oportunidade ou crescimento de investimento, foi utilizado o $q$ de Tobin,calculado por meio da Equação 10, conforme o estudo de Chung e Pruitt (1994):

$$
\operatorname{QTobin}_{i t}=\frac{V M A_{i t}+V P T_{i t}-A C_{i t}}{V A T_{i t}}
$$

Em que:

$Q_{i t}=q$ de Tobin da empresa $i$ no tempo $t$;

$V M A_{i t}=$ valor de mercado das ações ordinárias $(\mathrm{ON})$ e preferências $(\mathrm{PN})$ da empresa $i$ no tempo $t$;

$V P T_{i t}=$ valor contábil do passivo total da empresa $i$ no tempo $t$;

$A C_{i t}=$ valor contábil do ativo circulante da empresa $i$ no tempo $t$; e

$V A T_{i t}=$ valor contábil dos ativos da empresa $i$ no tempo $t$.

Ressalta-se que o valor de mercado das empresas que possuem ações de classe ON e PNfoi calculado conforme o estudo de Machado e Medeiros (2011). Caso a empresa não possua uma das duas classes, o valor será computado apenas com a classe da ação negociada.

Para representação de níveis de recursos gerados internamente, foi utilizado o fluxo de caixa $\left(F C_{i t}\right)$ das empresas ponderado pelo estoque de capital defasado $\left(K_{i t-1}\right)$, obtido pela Equação 11:

$$
R G I_{i t}=\frac{F C_{i t}}{K_{i t-1}}=\frac{L L_{i t}+D E P R E_{i t}+A M O R T_{i t}}{K_{i t-1}}
$$

Em que:

$R G I_{i t}=$ recurso gerado internamente da empresa $i$ no tempo $t$;

$F C_{i t}=$ fluxo de caixa para empresa $i$ no ano $t$;

$K_{i t-1}=$ estoque de capital da empresa $i$ no ano $t-1$;

$L L_{i t}=$ lucro líquido da empresa $i$ no ano $t$;

$D E P R E_{i t}=$ depreciação da empresa $i$ no ano $t$; e

$A M O R T_{i t}=$ amortização da empresa ino ano $t$.

Para a proxy de rentabilidade marginal do capital, foram utilizadas as vendasponderadas pelo estoque de capital defasado, conforme Equação 12: 


$$
R M C_{i t}=\frac{V d_{i t}}{K_{i t-1}}=\frac{R O B_{i t}}{K_{i t-1}}
$$

\section{Em que:}

$R M C_{i t}=$ rentabilidade marginal do capital da empresa $i$ no tempo $t$;

$V d_{i t}=$ vendas da empresa $i$ no tempo t;

$K_{i t-1}=$ estoque de capital da empresa $i$ no ano $t-1$; e

$R O B_{i t}=$ receita operacional bruta da empresa $i$ no tempo $t$.

Como proxy do nível de alavancagem, foi utilizado oíndice de endividamento, conforme Equação 13:

$$
E N D_{i t}=\frac{P T_{i t}}{A T_{i t}}
$$

Em que:

$E N D_{i t}=$ endividamento da empresa $i$ no tempo $t$;

$P T_{i t}=$ valor do passivo total da empresa $i$ no tempo $t$; e

$A T_{i t}=$ valor do ativo total da empresa $i$ no tempo $t$. 


\section{ANÁLISE DOS DADOS}

Com o objetivo de investigar o problema de pesquisa e de ratificar ou refutar as hipóteseslevantadas, esta seção apresenta as estatísticas descritivas dos dados e os resultados obtidos por meio de testes empíricos. Ressalta-se que todos os dados necessários foram coletados no banco de dados da empresaEconomatica ${ }^{\circledR}$, no dia 8 de setembro de 2015 , e do sítio da BM\&FBovespa, no período de $1^{\circ}$ de julho a 30 de julho de 2015.

A análise dos dados está dividida em três partes. A primeira apresenta as estatísticas descritivas das variáveis estudadas. A segunda parte descreve os resultados da regressão da Equação 4, visando verificar o efeito da incerteza sobre o nível de investimento.E a terceira apresenta os testes de robustez.

\subsection{ESTATÍSTICA DESCRITIVA}

A amostra analisada se constituiu de todas as empresas com ações negociadas na BM\&FBovespa, no período de 2008 a 2014, excluindo: (a) as financeiras;(b) as que não apresentaram valor de mercado no dia 31 de dezembro de cada ano;(c) as que não obtiveram 125 observações de retorno durante o ano; e (d) as que não apresentaram os dados necessários para a pesquisa.

Assim, de acordo com essas restrições, foram coletados os dados de 186 empresas, em média, conforme Tabela 3, representando 50,32\%, em média, da amostra inicial do estudo. Ressalta-se que a análise se iniciou em 2008, contudo, o ano de 2007 foi utilizado para calcular a ponderação das variáveis. Comparando com estudos internacionais, essa amostra apresenta tamanho reduzido. Tran (2014), por exemplo, analisou, em média, 553 empresas australianas, no período de 1987 a 2009. Quando comparada a estudos brasileiros, a presente amostra apresentou tamanho satisfatório. Pereira (2008), por exemplo, analisou, em média, 23 empresas brasileiras, no período de 1966 a 1995.

Tabela 3 - Amostra do estudo (2008-2014)

\begin{tabular}{cccc}
\hline Ano & Amostra Inicial & Amostra Final & \% da amostra inicial \\
\hline 2008 & 345 & 171 & 49,565 \\
2009 & 353 & 172 & 48,725 \\
2010 & 367 & 175 & 47,684 \\
2011 & 373 & 181 & 48,525 \\
2012 & 383 & 196 & 51,175 \\
2013 & 384 & 202 & 52,604 \\
2014 & 382 & 206 & 53,927 \\
\hline Média & $\mathbf{3 7 0}$ & $\mathbf{1 8 6}$ & $\mathbf{5 0 , 3 1 5}$ \\
\hline
\end{tabular}


$\mathrm{Na}$ Tabela 4,são apresentadas as estatísticas descritivas das variáveis utilizadas para o estudo, compreendendo média, mediana, desvio padrão, valor mínimo e valor máximo. Além disso, contém o número total de observações por variável. Quanto ao número de total de observações, verifica-se que a maioria das variáveis apresentou todas as observações anuais válidas (1303).

Tabela 4 - Estatística descritiva (2008-2014)

\begin{tabular}{lrrrrrr}
\multicolumn{1}{c}{ Variáveis } & Obs. & Média & Mediana & Desvio padrão & Mínimo & Máximo \\
\hline I/K & 1303 & 1,309 & 1,064 & 1,938 & 0,000 & 37,146 \\
QTobin & 1303 & 69,769 & 0,686 & $1.303,456$ & $-0,941$ & $39.824,670$ \\
RGI & 1278 & 14,731 & 0,414 & 194,985 & 0,000 & $5.564,770$ \\
RMC & 1302 & 37,284 & 2,733 & 559,275 & 0,000 & $19.891,500$ \\
END & 1303 & 1,665 & 0,599 & 17,129 & 0,003 & 481,224 \\
INC_Total & 1303 & 0,531 & 0,407 & 0,505 & 0,105 & 9,342 \\
INC_Merc (b) & 1303 & 0,150 & 0,122 & 0,154 & $-0,276$ & 3,345 \\
INC_Esp (b) & 1303 & 0,467 & 0,363 & 0,305 & 0,000 & 2,099 \\
INC_Merc (c) & 1303 & 0,054 & 0,047 & 0,190 & $-4,933$ & 1,039 \\
INC_Setor (c) & 1303 & 0,120 & 0,081 & 0,284 & $-0,598$ & 7,692 \\
INC_Esp (c) & 1303 & 0,455 & 0,354 & 0,303 & 0,104 & 2,246 \\
\hline NOE: I/K
\end{tabular}

Nota: I/K é o nível de investimento das organizações; QTobin é o q de Tobin; RGI são os recursos gerados internamente; RMC é a rentabilidade marginal de capital; END é o endividamento; INC_Total é a incerteza total; INC_Merc (b) é a incerteza de mercado calculada com a restrição $\gamma$ it $=0$ na Equação 3; INC_Esp (b) é a incerteza específica calculada com a restrição $\gamma \_\mathrm{it}=0$ na Equação 3; INC_Merc (c) é a incerteza de mercado calculada pelo modelo de dois índices; INC_Setor (c) é a incerteza do setor calculada pelo modelo de dois índices; e INC_Esp (c) é a incerteza específica calculada pelo modelo de dois índices.

De acordo com a Tabela 4, onível de investimento na amostra tem uma média de 1,309 e desvio padrão de 1,938, com valor mínimo de 0,000 e máximo de 37,146. Esses valores corroboram o estudo de Sâmam (2010), que analisou dados da Romênia no período de 2000 a 2008. Contudo, divergem dos estudos com empresas norte-americanas, como os de Bulan (2005) e Baum, Caglayan e Talavera (2008, 2010),que obtiveram resultados inferiores para o nível de investimento. Essa diferença pode ser justificada pelas particularidades do mercado de capitais e economia de cada país.

Quanto às proxies para incerteza, tem-se que a INC_Total apresentou uma média de 0,531, com um desvio padrão de 0,505 e valor de máximo e mínimo de 0,105 e 9,342, respectivamente, corroborando a pesquisa de Bulan (2005), para empresas norte-americanas, e a de Xu, Wang e Xin (2010), para empresas chinesas. Contudo, contrariou os estudos de Baum, Caglayan e Talavera $(2008,2010)$ para empresas norte-americanas, que apresentou resultados superiores $(0,849$, em média). Tal discrepância entre os estudos com empresas norte- americanas pode ser justificada pelo período em que o estudo foi realizado, uma vez que o de Bulan (2005) foi no período de 1966 a 1995. 
No que concerne às variáveis de INC_Merc (b) e INC_Esp (b),calculadas com base na restrição $\gamma_{i t}=0$ na Equação 3, observa-se uma média de 0,150 e 0,467, com um desvio em torno da média de 0,154 e 0,305, respectivamente. Esses resultados corroboram o estudo de Bulan (2005).Em relação aos regressores INC_Merc (c), INC_Setor (c) e INC_Esp (c), calculado pelo modelo de dois índices, observou-se que a média foi de 0,054, 0,120 e 0,455, respectivamente,sendo a INC_Esp (c) a que apresentou maior dispersão em torno da média (0,3030), condizente com os estudos de Bulan (2005) e de Xu, Wang e Xin (2010).

Quanto às demais variáveis, QTobin, RGI, RMC e END, verifica-se que possuem média e desvio padrão alto, quando comparadas às demais variáveis da pesquisa, fato que pode ser justificado pelas características das empresas brasileiras com papéis negociados na BM\&FBovespa e/ou pela presença de observações com valores aberrantes (possivelmente causados pelas mudanças dos padrões contábeis a partir de 2010/fullIFRS).

Com o objetivo de investigar as relações entre as variáveis do estudo, foi elaborada uma matriz de correlação de Pearson, a qual está representada na Tabela 5. Os resultados obtidos entre a correlação da variável dependente com as independentes são semelhantes ao da pesquisa de Bulan (2005), com exceção para as variáveis END e INC_Setor (c), que apresentaram correlação negativa. Contudo, tais variáveis corroboram o resultado apresentado na pesquisa de $\mathrm{Xu}$, Wang e Xin (2010).

Tabela 5 - Matriz de correlação de Pearson(2008-2014)

\begin{tabular}{|c|c|c|c|c|c|c|c|c|c|c|c|}
\hline Variáveis & (A) & (B) & (C) & (D) & (E) & (F) & (G) & (H) & (I) & (J) & (K) \\
\hline$\overline{(A)}$ & 1 & & & & & & & & & & \\
\hline (B) & $0,350 * * *$ & 1 & & & & & & & & & \\
\hline (C) & $0,065^{* *}$ & 0,012 & 1 & & & & & & & & \\
\hline (D) & $0,197 * * *$ & $-0,004$ & $0,386 * * *$ & 1 & & & & & & & \\
\hline (E) & $0,393 * * *$ & 0,012 & 0,001 & $-0,005$ & 1 & & & & & & \\
\hline (F) & 0,034 & $0,054^{*}$ & $-0,010$ & 0,008 & $0,107 * * *$ & 1 & & & & & \\
\hline (G) & $0,111 * * *$ & 0,039 & 0,006 & 0,022 & 0,029 & $0,198 * * *$ & 1 & & & & \\
\hline (H) & $0,068 * *$ & $0,093 * * *$ & $-0,012$ & 0,016 & $0,182 * * *$ & $0,628 * * *$ & $0,116 * * *$ & 1 & & & \\
\hline (I) & 0,022 & $-0,031$ & 0,017 & 0,004 & $0,051^{* *}$ & $-0,236 * * *$ & $-0,018$ & $-0,012$ & 1 & & \\
\hline (J) & $0,071^{* *}$ & $0,094 * * *$ & $-0,010$ & 0,011 & $-0,022$ & $0,343 * * *$ & $0,390 * * *$ & $0,110 * * *$ & $-0,788 * * *$ & 1 & \\
\hline (K) & $0,050 *$ & $0,050 *$ & $-0,011$ & 0,016 & $0,184 * * *$ & $0,632 * * *$ & $0,112 * * *$ & 0,965 & $-0,028$ & $0,007 * *$ & 1 \\
\hline
\end{tabular}

Nota: $(\mathrm{A})=\mathrm{I} / \mathrm{K}$ é o nível de investimento das organizações; (B) = QTobin é o $q$ de Tobin; (C) = RGI são os recursos gerados internamente; $(\mathrm{D})=\mathrm{RMC}$ é a rentabilidade marginal de capital; $(\mathrm{E})=\mathrm{END}$ é o endividamento; $(\mathrm{F})=$ INC_Total é a incerteza total; $(\mathrm{G})=$ INC_Merc (b) é a incerteza de mercado calculada com a restrição $\gamma_{i t}=0$ na Equação 3; $(\mathrm{H})=$ INC_Esp (b) é a incerteza específica calculada com a restrição $\gamma_{i t}=0$ na Equação 3; (I) = INC_Merc (c) é a incerteza de mercado calculada pelo modelo de dois índices; (J) = INC_Setor (c) é a incerteza do setor calculada pelo modelo de dois índices; e (K) = INC_Esp (c) é a incerteza específica calculada pelo modelo de dois índices.

*** significante ao nível de 1\%; * significante ao nível de 5\%; * significante ao nível de $10 \%$

Quanto às variáveis de incerteza, verifica-se que a INC_Total (F) tem alta correlação com as demais medidas de incerteza, indicando que a INC_Total (F) captura fatores de 
incerteza que estão incluídos nas demais medidas de incerteza, conforme esperado. Esses achados são condizentes com os estudos de Bulan (2005) e Xu, Wang e Xin (2010).

Analisando-se especificamente cada medida, verifica-se que: (1) A INC_Merc (b) não é correlacionada com a INC_Merc (c); (2) a INC_Esp (b) não é correlacionada com INC_Merc (c) e INC_Esp (c); e (3) a INC_Merc (c) não é correlacionada com a INC_Esp (c). Assim, temse que essas proxies capturam fatores diferentes de incerteza. Os resultados apresentados divergem parcialmente dos encontrados por Bulan (2005) para empresas americanas.

Destaca-se, conforme a Tabela 5, a existência de correlação entre algumas das variáveis independentes, sendo assim, investigou-se previamente a possibilidade de multicolinearidade para os modelos (a), (b) e (c), que serão analisados na subseção 4.2. Para tanto, foi realizado o teste do fator de inflação da variável (VIF) e o tolerance, cujos resultados são apresentados na Tabela 6 .

Tabela 6 - Testes de multicolinearidade (2008-2014)

\begin{tabular}{|c|c|c|c|c|c|c|}
\hline \multirow{2}{*}{ Variáveis } & \multicolumn{2}{|c|}{ (a) } & \multicolumn{2}{|c|}{ (b) } & \multicolumn{2}{|r|}{ (c) } \\
\hline & VIF & Tolerance & VIF & Tolerance & VIF & Tolerance \\
\hline QTobin & 1,00 & 0,997 & 1,01 & 0,990 & 1,02 & 0,958 \\
\hline RGI & 1,18 & 0,850 & 1,18 & 0,850 & 1,18 & 0,850 \\
\hline RMC & 1,18 & 0,850 & 1,18 & 0,850 & 1,18 & 0,850 \\
\hline END & 1,01 & 0,988 & 1,03 & 0,967 & 1,04 & 0,958 \\
\hline INC_Total & 1,01 & 0,988 & - & - & - & - \\
\hline INC_ Merc & - & - & 1,01 & 0,985 & 2,66 & 0,376 \\
\hline INC_Setor & - & - & - & - & 2,68 & 0,372 \\
\hline INC_Esp & - & - & 1,06 & 0,946 & 1,04 & 0,958 \\
\hline
\end{tabular}

Nota: I/K é o nível de investimento das organizações; QTobin é o $q$ de Tobin; RGI são os recursos gerados internamente; RMC é a rentabilidade marginal de capital; END é o endividamento; INC_Total é a incerteza total; INC_Merc (b) é a incerteza de mercado calculada com a restrição $\gamma_{i t}=0$ na Equação 3; INC_Esp (b) é a incerteza específica calculada com a restrição $\gamma_{i t}=0$ na Equação 3; INC_Merc (c) é a incerteza de mercado calculada pelo modelo de dois índices; INC_Setor (c) é a incerteza do setor calculada pelo modelo de dois índices; e INC_Esp (c) é a incerteza específica calculada pelo modelo de dois índices.

Observa-se, com base na Tabela 6, que os valores obtidos para a estatística VIF, em todos os modelos analisados, situam-se próximo a 1, o que permite assegurar a inexistência de colinearidade entre as variáveis explicativas nos modelos analisados. Concomitantemente, analisando-se pela estatística tolerance, os resultados também asseguram a inexistência de colinearidade entre as variáveis explicativas. Por fim, essa detecção assegura o uso de modelos de regressão múltipla de forma mais consistente. 


\subsection{INCERTEZA E INVESTIMENTO}

Nesta seção, são apresentados os resultados da estimação da Equação 4, que verifica o efeito da incerteza sobre o nível de investimento, com diferentes proxies para incerteza. No modelo (a), usa-se a volatilidade do retorno total das ações comoproxypara incerteza total da empresa, enquanto o modelo (b) decompõe a incerteza total em seus componentes de mercado e específico da firma, conforme a restrição $\gamma_{i t}=0$ imposta na Equação 3. Por sua vez, omodelo (c) decompõe a incerteza total em três componentes: o de mercado, o da indústria e o específico da firma, conforme modelo de dois índices da Equação 3.

Especificamente, na Tabela 7, constam os valores dos coeficientes estimados, o $\mathrm{R}^{2}$, a estatística F, a estatística do teste de normalidade de Jarque-Bera, a estatística de heterocedasticidade de White e, por fim, a estatística do teste de autocorrelação de Wooldridge. Os valores que se encontram entre parênteses correspondem ao $p$-valor de cada teste específico.

Tabela 7 - Efeito da incerteza sobre o nível de investimento das empresas (2008-2014)

\begin{tabular}{|c|c|c|c|}
\hline Variáveis & (a) ${ }^{1}$ & $\left(\right.$ b) ${ }^{1}$ & $(c)^{1}$ \\
\hline \multirow[t]{2}{*}{ QTobin } & $0,0005^{* * *} *$ & $0,0005 * * *$ & $0,0005 * * *$ \\
\hline & $(0,000)$ & $(0,000)$ & $(0,000)$ \\
\hline \multirow[t]{2}{*}{ RGI } & $-0,0002 * * *$ & $-0,0002 * * *$ & $-0,0002 * * *$ \\
\hline & $(0,000)$ & $(0,000)$ & $(0,000)$ \\
\hline \multirow[t]{2}{*}{ RMC } & $0,0006 * * *$ & $0,0007 * * *$ & $0,0007 * * *$ \\
\hline & $(0,000)$ & $(0,000)$ & $(0,000)$ \\
\hline \multirow{2}{*}{ END } & $0,0447 * *$ & $0,0451 * * *$ & $0,0450 * * *$ \\
\hline & $(0,011)$ & $(0,010)$ & $(0,010)$ \\
\hline \multirow[t]{2}{*}{ INC_Total } & $-0,2567 * * *$ & - & - \\
\hline & $(0,006)$ & & \\
\hline \multirow[t]{2}{*}{ INC_Mer } & - & 0,6090 & 0,3911 \\
\hline & & $(0,203)$ & $(0,464)$ \\
\hline \multirow{2}{*}{ INC_Setor } & - & - & 0,1202 \\
\hline & & & $(0,767)$ \\
\hline \multirow[t]{2}{*}{ INC_Esp } & - & $-0,4706^{* * *}$ & $-0,4328 * * *$ \\
\hline & & $(0,006)$ & $(0,004)$ \\
\hline \multirow[t]{2}{*}{ Intercepto } & $1,0479 * * *$ & $1,0822 * * *$ & $1,0915 * * *$ \\
\hline & $(0,000)$ & $(0,000)$ & $(0,000)$ \\
\hline $\mathbf{R}^{2}$ & 0,3570 & 0,3593 & 0,3576 \\
\hline \multirow[t]{2}{*}{ Teste F } & 23,33 & 25,51 & 22,80 \\
\hline & $(0,000)$ & $(0,000)$ & $(0,000)$ \\
\hline \multirow[t]{2}{*}{ Jarque-Bera } & $19 \mathrm{e}+06$ & $1,8 \mathrm{e}+06$ & $1,8 \mathrm{e}+06$ \\
\hline & $(0,000)$ & $(0,000)$ & $(0,000)$ \\
\hline \multirow[t]{2}{*}{ White } & 597,42 & 674,723 & 747,83 \\
\hline & $(0,000)$ & $(0,000)$ & $(0,000)$ \\
\hline \multirow[t]{2}{*}{ Wooldridge } & 26,05 & 26,74 & 36,633 \\
\hline & $(0,000)$ & $(0,000)$ & $(0,000)$ \\
\hline Observações & 1.278 & 1.278 & 1.278 \\
\hline
\end{tabular}

Nota:(1) Erros padrões estimados com correção para heterocedasticidade e correlação serial usando Newey-West com 1 lag;

*** significante ao nível de $1 \%$;* significante ao nível de 5\%; * significante ao nível de $10 \%$. 
Conforme se observa na Tabela 7 , as regressões para todos os modelos mostraram-se significativas em termos estatísticos, ao nível de 1\%, conforme teste F. Além disso, verificase que a hipótese de homocedasticidade das variâncias foi rejeitada, ao nível de 1\%, para todos os modelos, assim como a hipótese nula de correlação serial. Por isso, os errospadrões foram estimados usando Newey-West com 1lag. Quanto ao teste de Jarque-Bera, nota-se que a hipótese nula de que os resíduos se distribuem normalmente foi rejeitada ao nível de $1 \%$. Entretanto, conforme o teorema do limite central e considerando que foram utilizadas 1.278 observações, o pressuposto pode ser relaxado (BROOKS, 2008). Por fim, observa-se que o coeficiente de determinação $\left(\mathrm{R}^{2}\right)$ para os modelos estimados apresenta um poder explicativo médio de 0,3579 .

No modelo (a), verifica-se que a incerteza total tem um efeito negativo e significativo sobre nível de investimento das empresas, isto é, um aumento de $1 \%$ na incerteza total da empresa diminui o nível de investimento em 0,2567\%. Esses resultados são condizentes com a TOR, que defende que,em elevados níveis de incerteza, a opção de adiar um investimento é valiosa, e corroboram os achados de Bulan (2005), Baum, Caglayan e Talavera (2008, 2010), para o mercado norte-americano, os de Bloom, Bom e Reenem (2007), para o mercado do Reino Unido,os de Xu Wang e Xin (2010), para o mercado chinês, e os de Tran (2014), para o mercado australiano.

Especificamente, Xu, Wang e Xin (2010) evidenciaram que um aumento de $1 \%$ na incerteza total para as empresas chinesas diminuía o investimento em $0,155 \%$, enquanto Bulan (2005) verificou que um aumento de $1 \%$ na incerteza total reduz o nível de investimento em 0,4732\%.Observa-se, de acordo com os estudos analisados, que a incerteza total tem um maior impacto sobre o nível de investimento das empresas norte-americanas, em relação às empresas chinesas e brasileiras.

No modelo (b),tem-se que a incerteza de mercado obteve um coeficiente positivo e não significativo sobre o nível de investimento, contrariando o efeito esperado, tendo em vista que, segundo a teoria tradicional,a incerteza de mercado deveria afetar negativamente o nível de investimento,por meio da taxa de desconto (custo de capital). Contudo, diversos outros estudos analisados neste trabalho encontraram resultados semelhantes. Bulan (2005)e Baum, Caglayan e Talavera (2008), por exemplo, analisando empresas norte-americanas, verificaram um efeito positivo e significativo da incerteza de mercado sobre o investimento, enquanto Leahy e Whited (1996) e Xu, Wang e Xin (2010) não encontraram um efeito significativo da incerteza de mercado sobre o nível de investimento das empresas chinesas. 
Quanto à incerteza específica, com base na restrição $\gamma_{i t}=0$ imposta na Equação 3, modelo (b), observa-se que apresentou um coeficiente negativo e significativo sobre o nível de investimento, inclusive com um efeito superior ao da incerteza total, uma vez que o aumento de $1 \%$ na incerteza específica reduz o nível de investimento em 0,4796\%. Esse resultado é consistente com a TOR, que defende que a incerteza específica tem efeito negativo sobre o investimento, devido ao capital específico da firma ser irreversível.Os estudos de Bulan (2005), Xu, Wang e Xin (2010) e Tran (2010) apresentaram resultados semelhantes, inclusive quanto à intensidade do efeito da incerteza específica, quando comparado à da incerteza total.

No modelo (c),percebe-se que apenas a incerteza específica da firma apresentou um efeito negativo e significativo sobre os investimentos, isto é, um aumento de $1 \%$ na incerteza reduz o investimento em 0,4328; os demais componentes de riscos apresentaram um efeito positivo e não significativo, corroborando os achados de Xu, Wang e Xin (2010) para o mercado chinês e contrariando os achados de Tran (2014) para o mercado australiano. Contudo, ressalta-se que esses resultados corroboram parcialmente os achados de Bulan (2005) para o mercado norte-americano no período de 1966-1999, uma vez que, em seu estudo, apenas as incertezas da indústria e específica da firma apresentaram um efeito negativo e significativo.

Resumidamente, com base nos três modelos ((a), (b) e (c)), é possível verificar que a incerteza total tem um efeito negativo e significativo sobre o nível de investimento, corroborando os achados de Bulan (2005), para empresas norte-americanas, Bloom, Bond e Reenen (2007), para as empresas do Reino Unido, Xu, Wang e Xin (2010), para empresas chinesas, e Tran (2014), para o mercado australiano. No entanto, quanto às demais medidas de incerteza, apenas a incerteza específica apresentou um efeito negativo e significativo, conforme o estudo de Xu, Wang e Xin (2010), no mercado chinês. Esse último resultado confirma que o efeito negativo da incerteza que importa para o nível de investimento é o especifico da firma, condizente com o previsto pelaTOR.

Convém destacar que em todos os modelos analisados as variáveis explicativas $q$ de Tobin, recursos gerados internamente (RGI), rentabilidade marginal de capital (RMC) e endividamento (END) obtiveramcoeficientes muito similares e significantes estatisticamente. Porém, as variáveis RGI e END apresentaram sinal contrário ao esperado. Esse fato pode ser justificado pelas particularidades da economia brasileira.

Especificamente, os recursos gerados internamente deveriam ter um efeito positivo sobre o nível de investimento, tendo em vista que, de acordo com a POT, as empresas 
inicialmente se financiam por recursos próprios, no entanto, devido aos benefícios fiscais brasileiros para a capitação de recursos de terceiros, esse resultado pode ser inverso ao esperado. Além disso, as organizações brasileiras podem ter uma política rigorosa de dividendos, logo, dando preferência pelo pagamento de dividendos em detrimento ao financiamento por recursos próprios.

Em relação à variável endividamento, esperava-se um efeito negativo, uma vez que as empresas mais alavancadas apresentam conflito de interesse entre os detentores de capital e os de dívida, fazendo com que os gestores evitem projetos com VPL positivo em altos níveis de endividamento. No entanto, é comum as empresas brasileiras possuírem altos níveis de endividamento (INSTITUTO ASSAF, 2015), impulsionado, inclusive, pelo benefício fiscal.

\subsection{ANÁLISE DE ROBUSTEZ}

\subsubsection{Tamanho da empresa}

Nesta subseção,explorou-se o efeito do tamanho da empresa sobre a relação entre incerteza e investimento, conforme os estudos de Bulan (2005), Panousi e Papanikolaou (2012), Czarnitzki e Toole (2013) e Tran (2014). Para Panousi e Papanikolaou (2012) e Tran (2014), o tamanho da empresa representa uma proxy para restrição financeira e assimetria informacional entre o credor e devedor. Dessa forma, espera-se que as empresas mais restritas (menores empresas) tenham um maior impacto da incerteza sobre o nível de investimento do que as empresas irrestritas (maiores empresas).

Como proxy para tamanho da empresa,utilizou-se o logaritmo natural do ativo total (LNAT), conforme Bulan (2005) e Tran (2014). Nesse sentido, as empresas foram agrupadas com base na mediana do LNAT, isto é, empresas com LNAT $\geq$ mediana foram classificadas como firmas maiores, e os demais casos como firmas menores.

A Tabela 8 apresenta os resultados da estimativa da Equação 4, com diferentes proxies para incerteza, para as firmas maiores e as menores. Nela, constam os valores dos coeficientes estimados, o coeficiente de determinação, a estatística F, a estatística do teste de normalidade de Jarque-Bera, a estatística de heterocedasticidade de White e, por fim, a estatística do teste de autocorrelação de Wooldridge.

Assim, conforme Tabela 8, constata-se que todos os modelos são significativos estatisticamente, segundo o teste F. Além disso, observa-se, conforme o teste de Jarque-Bera, que os resíduos da regressão não possuem uma distribuição normal, no entanto, com base no 
teorema do limite central, esse pressuposto pode ser relaxado (BROOKS, 2008). Quanto ao teste de White, verifica-se que, para todos os modelos, a hipótese nula de homocedasticidade foi rejeitada. No que concerne ao teste de Wooldridge, nota-se que,para firmas maiores, a hipótese nula de ausência de correlação serial não pode ser rejeitada.Dessa forma, os erros padrõesdos coeficientes para firmas maiores foram ajustados, usando os erros padrões de Huber-White e os coeficientes para as firmas menoresusando Newey-West com 1lag, para correção de heterocedasticidade e correlação serial.Os valores que se encontram entre parênteses correspondem ao $p$-valor de cada teste específico.

Tabela 8 - Efeito da incerteza sobre o nível de investimento para firmas maiores e menores (2008-2014)

\begin{tabular}{|c|c|c|c|c|c|c|}
\hline \multirow{2}{*}{ VARIÁVEIS } & \multicolumn{3}{|c|}{ Firmas Maiores } & \multicolumn{3}{|c|}{ Firmas Menores } \\
\hline & $(\mathbf{a})^{2}$ & $(\mathbf{b})^{2}$ & $(\mathbf{c})^{2}$ & $(\mathbf{a})^{1}$ & $(\mathbf{b})^{1}$ & $(c)^{1}$ \\
\hline \multirow[t]{2}{*}{ QTobin } & $-0,0002$ & 0,0000 & $-0,0003$ & $0,0005 * * *$ & $0,0005 * * *$ & $0,0005 * * *$ \\
\hline & $(0,706)$ & $(0,915)$ & $(0,668)$ & $(0,000)$ & $(0,000)$ & $(0,000)$ \\
\hline \multirow[t]{2}{*}{ RGI } & 0,0319 & 0,0306 & 0,0314 & $-0,0002 * * *$ & $-0,0002 * * *$ & $-0,0002 * * *$ \\
\hline & $(0,120)$ & $(0,117)$ & $(0,120)$ & $(0,000)$ & $(0,000)$ & $(0,000)$ \\
\hline \multirow[t]{2}{*}{ RMC } & $-0,0008$ & $-0,0010$ & $-0,0010$ & $0,0007 * * *$ & $0,0007 * * *$ & $0,0007 * * *$ \\
\hline & $(0,531)$ & $(0,423)$ & $(0,456)$ & $(0,000)$ & $(0,000)$ & $(0,000)$ \\
\hline \multirow[t]{2}{*}{ END } & $-0,8977 * *$ & $-1,0927 * *$ & $-1,1137 * *$ & $0,0447 * * *$ & $0,0450 * * *$ & $0,0452 * *$ \\
\hline & $(0,050)$ & $(0,018)$ & $(0,015)$ & $(0,010)$ & $(0,009)$ & $(0,009)$ \\
\hline INC_Total & $\begin{array}{l}0,004 \\
(0,942)\end{array}$ & - & - & $\begin{array}{l}-0,3261 * * \\
(0,046)\end{array}$ & - & - \\
\hline \multirow[t]{2}{*}{ INC_Mer } & - & 1,6290 & 0,7438 & - & 0,0752 & $-0,5314$ \\
\hline & & $(0,178)$ & $(0,427)$ & & $(0,628)$ & $(0,341)$ \\
\hline \multirow[t]{2}{*}{ INC_Setor } & - & - & 0,8165 & - & - & $-0,3839$ \\
\hline & & & $(0,262)$ & & & $(0,452)$ \\
\hline \multirow[t]{2}{*}{ INC_Esp } & - & 0,3437 & $0,5882 *$ & - & $-0,4548 * *$ & $-0,4122 * *$ \\
\hline & & $(0,310)$ & $(0,093)$ & & $(0,038)$ & $(0,031)$ \\
\hline \multirow[t]{2}{*}{ Intercepto } & $1,5422 * * *$ & $1,3180 * * *$ & $1,3355 * * *$ & $1,0621 * * *$ & $1,1306 * * *$ & $1,1475 * * *$ \\
\hline & $(0,000)$ & $(0,000)$ & $(0,000)$ & $(0,000)$ & $(0,000)$ & $(0,000)$ \\
\hline $\mathbf{R}^{2}$ & 0,1464 & 0,1556 & 0,1526 & 0,5851 & 0,5861 & 0,5862 \\
\hline \multirow[t]{2}{*}{ Teste F } & 2,66 & 2,52 & 2,43 & 187,00 & 195,08 & 175,43 \\
\hline & $(0,000)$ & $(0,000)$ & $(0,000)$ & $(0,000)$ & $(0,000)$ & $(0,000)$ \\
\hline \multirow[t]{2}{*}{ Jarque-Bera } & $1,2 \mathrm{e}+06$ & $1,2 \mathrm{e}+06$ & $1,2 \mathrm{e}+06$ & $1,0 \mathrm{e}+05$ & $1,2 \mathrm{e}+05$ & $1,2 \mathrm{e}+05$ \\
\hline & $(0,000)$ & $(0,000)$ & $(0,000)$ & $(0,000)$ & $(0,000)$ & $(0,000)$ \\
\hline \multirow[t]{2}{*}{ White } & 516,39 & 551,13 & 552,48 & 582,18 & 585,39 & 588,09 \\
\hline & $(0,000)$ & $(0,000)$ & $(0,000)$ & $(0,000)$ & $(0,000)$ & $(0,000)$ \\
\hline \multirow[t]{2}{*}{ Wooldridge } & 0,114 & 0,048 & 0,087 & 5,282 & 5,181 & 6,943 \\
\hline & $(0,736)$ & $(0,827)$ & $(0,7686)$ & $(0,024)$ & $(0,025)$ & $(0,009)$ \\
\hline Observações & 640 & 640 & 640 & 638 & 638 & 638 \\
\hline
\end{tabular}

Nota: (1) Erros padrões estimados com correção para heterocedasticidade e correlação serial usando Newey-West com 1 lag;

(2) Erros padrões estimados com correção para heterocedasticidade usando Huber-White;

*** significante ao nível de $1 \%$; ** significante ao nível de 5\%; * significante ao nível de $10 \%$.

Observa-se que o coeficiente de determinação para os modelos analisados variam de 0,1464 a 0,5862 , apresentando um poder explicativo médio de 0,3687 , sendo os modelos de firmas maiores os que obtiveram menores coeficientes de determinação, e os de firmas 
menores os maiores coeficientes de determinação. Tal disparidade entre os coeficientes de determinação entre os grupos de firmas, maiores e menores, justifica-se pelo fato de que, para firmas maiores, grande parte das variáveis não apresentoup-valor significativo estatisticamente.

Na Tabela 8, percebe-se, ainda, que para o grupo com as firmas maiores, a incerteza total, modelo (a), não teve um efeito significativo estatisticamente sobre o nível de investimento, corroborando o estudo de Tran (2014), para empresas australianas, e contrariando os achados de Bulan (2005), para empresas norte-americanas. Quanto ao modelo (b), constata-se que as incertezas de mercado e a específica também não apresentaram efeito significativo sobre o investimento. Bulan (2005) obteve resultados parecidos, um efeito não significativo para a incerteza de mercado e um efeito negativo e significativo para a incerteza específica. No que concerne ao modelo (c), constata-se que a incerteza específica tem um efeito negativo e significativo sobre o investimento, corroborando os achados de Bulan (2005).

No que concerne ao grupo com as menores firmas, constata-se que a incerteza total, modelo (a), tem um efeito negativo e significativo sobre o nível de investimento, condizente com os estudos de Bulan (2005), para o mercado norte-americano, e o de Tran (2014), para o mercado australiano. No modelo (b),a incerteza de mercado não apresentou coeficiente significativamente diferente de 0 , enquanto que a incerteza específica da firma evidenciou um coeficiente significativo em termos estatísticos ao nível de significância de 5\%. Esses achados estão condizentes com o estudo de Bulan (2005), para as empresas norte-americanas. Por fim, o modelo (c) obteve um efeito negativo e significativo da incerteza específica da firma sobre os investimentos, conforme os resultados obtidos por Bulan (2005).

Resumidamente, verifica-se que as firmas menores são mais sensíveis à incerteza, mudanças no ambiente de negócio, do que as firmas maiores, o que significa que a incerteza desempenha um maior papel nas decisões de investimento de empresas financeiramente restritas, em comparação com empresas irrestritas. Esses resultados corroboram os achados de Panousi e Papanikolaou (2012), para empresas norte-americanas, e Tran (2014), para empresas australianas, e contrariam os de Bulan (2005), para o mercado norte-americano.

\subsubsection{Efeito da competitividade}

Conforme a TOR, a concorrência entre as empresas pode inibir a opção de adiar um investimento, uma vez que as organizações, para não perderem a competitividade dentro do 
mercado e, consequentemente, os fluxos de caixa futuros de investimento, podem adiantar a opção de investir (TRIGEORGIS, 1996; BULAN, 2005; BULAN; MAYER; SOMERVILLE 2009, PANOUSI; PAPANIKOLAOU, 2012; CZARNITZKI; TOOLE, 2013).Nesse sentido, espera-se que as empresas mais competitivas tenham um menor impacto da incerteza sobre o nível de investimento.

Para tanto, a amostra do estudo foi segregada entre empresas mais competitivas e menos competitivas. Para tanto, foi utilizada como proxy para competitividade o índice de Herfindahl-Hirschman (HHI), conforme Panousi e Papanikolaou (2012) e Czarnitzki e Toole (2013). A segregação das firmas como mais competitivas e menos competitivas foi feita com base na mediana do índice, isto é, as empresas com valor igual ou superior à mediana de HHI para a amostra foram classificadas como menos competitivas, pois são organizações mais concentradas, enquanto que as empresas com HHI inferior à mediana, como menos competitivas.

Tabela 9-Efeito da incerteza sobre o nível de investimentopara firmas mais competitivas e menos competitivas (2008-2014)

\begin{tabular}{|c|c|c|c|c|c|c|}
\hline \multirow{2}{*}{ Variáveis } & \multicolumn{3}{|c|}{ Mais competitiva } & \multicolumn{3}{|c|}{ Menos competitiva } \\
\hline & $(\mathbf{a})^{1}$ & $(\mathbf{b})^{1}$ & $(c)^{1}$ & $(\mathbf{a})^{1}$ & $(\mathbf{b})^{1}$ & $(\text { c) })^{1}$ \\
\hline QTobin & $0,0010^{* * *}$ & $0,0011 * * *$ & $0,0011 * * *$ & $0,0004 * * *$ & $0,0004 * * *$ & $0,0004 * * *$ \\
\hline & $(0,000)$ & $(0,000)$ & $(0,000)$ & $(0,000)$ & $(0,000)$ & $(0,000)$ \\
\hline RGI & $-0,0003$ & $-0,0003$ & $-0,0003^{*}$ & $-0,0002 * * *$ & $-0,0002 * * *$ & $-0,002 * * *$ \\
\hline & $(0,110)$ & $(0,115)$ & $(0,094)$ & $(0,000)$ & $(0,000)$ & $(0,000)$ \\
\hline RMC & $0,0007 * * *$ & $0,0007 * * *$ & $0,0007 * * *$ & $0,0026 * *$ & $0,0024 * *$ & 0,0025 \\
\hline & $(0,000)$ & $(0,000)$ & $(0,000)$ & $(0,019)$ & $(0,023)$ & $(0,019)$ \\
\hline END & $0,0476 * * *$ & $0,0483 * * *$ & $0,0484^{* * *}$ & $-0,0114 * * *$ & $-0,0107 * * *$ & $-0,0148 * * *$ \\
\hline & $(0,004)$ & $(0,003)$ & $(0,003)$ & $(0,000)$ & $(0,000)$ & $(0,000)$ \\
\hline INC_Total & $\begin{array}{l}-0,2701 * * \\
(0,015)\end{array}$ & - & - & $\begin{array}{l}-0,1701 \\
(0,118)\end{array}$ & - & - \\
\hline INC_Mer & - & $\begin{array}{l}0,0695 \\
(0,906)\end{array}$ & $\begin{array}{l}-0,1215 \\
(0,845)\end{array}$ & - & $\begin{array}{l}0,8971 \\
(0,234)\end{array}$ & $\begin{array}{l}0,7627 \\
(0,171)\end{array}$ \\
\hline INC_Setor & - & - & $\begin{array}{l}-0,1680 \\
(0,703)\end{array}$ & - & - & $\begin{array}{r}0,0829 \\
(0,918)\end{array}$ \\
\hline INC_Esp & - & $\begin{array}{l}-0,5508^{* * * *} \\
(0,002)\end{array}$ & $\begin{array}{l}-0,5674 * * * \\
(0,001)\end{array}$ & - & $\begin{array}{c}-0,3745 \\
(0,185)\end{array}$ & $\begin{array}{l}-0,1887 \\
(0,407)\end{array}$ \\
\hline Intercepto & $\begin{array}{l}1,0518^{* * *} \\
(0,000)\end{array}$ & $\begin{array}{l}1,1805^{* * *} \\
(0,000)\end{array}$ & $\begin{array}{l}1,2235^{* * *} \\
(0,000)\end{array}$ & $\begin{array}{l}1,0550 \text { **** } \\
(0,000)\end{array}$ & $\begin{array}{r}1,0601 \\
(0,000) \\
\end{array}$ & $\begin{array}{l}1,0170^{* * *} \\
(0,000)\end{array}$ \\
\hline $\mathbf{R}^{2}$ & 0,5717 & 0,5732 & 0,5742 & 0,2101 & 0,2170 & 0,2108 \\
\hline Teste F & $\begin{array}{c}51,08 \\
(0,000)\end{array}$ & $\begin{array}{c}56,93 \\
(0,000)\end{array}$ & $\begin{array}{c}52,55 \\
(0,000)\end{array}$ & $\begin{array}{c}7,84 \\
(0,000)\end{array}$ & $\begin{array}{c}7,49 \\
(0,000)\end{array}$ & $\begin{array}{c}7,01 \\
(0,000)\end{array}$ \\
\hline Jarque-Bera & $\begin{array}{c}1,0 \mathrm{e}+05 \\
(0,000)\end{array}$ & $\begin{array}{l}1,0 \mathrm{e}+05 \\
(0,000)\end{array}$ & $\begin{array}{l}1,0 \mathrm{e}+05 \\
(0,000)\end{array}$ & $\begin{array}{c}1,8 \mathrm{e}+06 \\
(0,000)\end{array}$ & $\begin{array}{l}1.8 \mathrm{e}+06 \\
(0,000)\end{array}$ & $\begin{array}{l}1.8 \mathrm{e}+06 \\
(0,000)\end{array}$ \\
\hline White & $\begin{array}{l}545,34 \\
(0,000)\end{array}$ & $\begin{array}{l}555,31 \\
(0,000)\end{array}$ & $\begin{array}{l}557,63 \\
(0,000)\end{array}$ & $\begin{array}{l}678,46 \\
(0,000)\end{array}$ & $\begin{array}{l}680,94 \\
(0,000)\end{array}$ & $\begin{array}{l}681,26 \\
(0,000)\end{array}$ \\
\hline Wooldridge & $\begin{array}{c}23,39 \\
(0,000)\end{array}$ & $\begin{array}{c}24,42 \\
(0,000)\end{array}$ & $\begin{array}{c}24,62 \\
(0,000)\end{array}$ & $\begin{array}{c}6,78 \\
(0,011)\end{array}$ & $\begin{array}{c}6,866 \\
(0,011)\end{array}$ & $\begin{array}{c}6,730 \\
(0,011)\end{array}$ \\
\hline Observações & 590 & 590 & 590 & 688 & 688 & 688 \\
\hline
\end{tabular}

Nota: (1) Erros padrões estimados com correção para heterocedasticidade e correlação serial usando Newey-West com 1 lag;

*** significante ao nível de 1\%; ** significante ao nível de 5\%; * significante ao nível de $10 \%$. 
Assim, na Tabela 9, são apresentados os resultados da estimativa da Equação 4 para cada grupo de empresas (mais competitivas e menos competitivas) com diferentes proxies para incerteza. Nela, constam os valores dos coeficientes estimados, o $\mathrm{R}^{2}$, a estatística $\mathrm{F}$, a estatística do teste de normalidade de Jarque-Bera, a estatística de heterocedasticidade de White e, por fim, a estatística do teste de autocorrelação de Wooldridge.Os valores que se encontram entre parênteses correspondem ao $p$-valor de cada teste específico.

Conformese observa na Tabela 9, a regressão para todos os modelos mostrou-se significativa em termos estatísticos, ao nível de $1 \%$, de acordo com reste F. Além disso, verifica-se que a hipótese de homocedasticidade das variâncias foi rejeitada, ao nível de $1 \%$, para todos os modelos, assim como a hipótese nula de que os resíduos se distribuem normalmente (teste de Jarque-Bera). Contudo, conforme o teorema do limite, o pressuposto pode ser relaxado (BROOKS, 2008). Quanto à hipótese nula de autocorrelação, percebe-se que a hipótese nula foi rejeitada para todos os modelos, sendo assim, os erros padrões foram estimados usando Newey-West com 1lag. Em relação ao coeficiente de determinação, percebe-se que varia de 0,2101 a 0,5742 .

Observa-se, ainda, que para as empresas mais competitivas, a incerteza total tem um efeito negativo e significativo, conforme modelo (a). Contudo, quando à incerteza total, é decomposta em seus componentes de mercado e específico da firma, com a restrição $\gamma_{i t}=0$ imposta na Equação 3, modelo (b), verifica-se que apenas a incerteza específica apresenta significância estatística, especificamente, um efeito negativo. Por fim, quanto ao modelo (c), nota-se que a incerteza de mercado e do setor não apresentaram resultados diferentes de 0 , enquanto que a incerteza específica tem um efeito negativo e significativo a $1 \%$ sobre o nível de investimento. Esses resultados contrariam os achados de Bulan (2005), para o mercado norte-americano, uma vez que não foi obtida significância estatística para as medidas de incerteza. Contudo, estão condizentes com os resultados encontrados nesta pesquisa para a amostra completa, conforme Tabela 7.

No que concerne às empresas menos competitivas, verifica-se que, para nenhum dos três modelos, a incerteza teve um efeito significativo estatisticamente sobre o nível de investimento. Esses resultados contrariam os encontrados por Bulan (2005), que obteve resultados inversos, isto é, efeito significativo para empresas menos competitivas e não significativo para empresas mais competitivas, assim como a TOR, uma vez que era esperado que as empresas mais competitivas sofressem um menor impacto da incerteza quando comparadas com as empresas menos competitivas. 
No entanto, destaca-se que esses resultados divergentes podem ter sido causados pela fragilidade da proxy utilizada para competitividade, uma vez que a classificação é feita por setor e não por empresa individualmente, como no caso do estudo de Bulan (2005). Outras proxies para competitividade não foram utilizadas devido à escassez de informações para o mercado brasileiro. Adicionalmente, o fato de as empresas mais competitivas terem um maior impacto da incerteza pode ser justificado como uma particularidade do mercado brasileiro, os investidores, devido à menor concentração do mercado e, consequentemente, maior competitividade, podem evitar assumir grandes riscos em relação ao fluxo de caixa futuro de novos investimentos.

\subsubsection{Quebra estrutural - fullIFRS}

Nesta seção,são apresentados os resultados da Equação 4 para o marco temporal de 2010 a 2014. Essa quebra estrutural foi realizada em virtude da adoção da International Financial Reporting Standards (IFRS) pelas empresas brasileiras que alteraram as políticas contábeis do país, especificamente a forma de reconhecimento, mensuração e evidenciação dos elementos contábeis. Sendo assim, por serem utilizados dados contábeis neste estudo, fezse necessária a analise particular desse marco temporal.

Desta forma, a Tabela 10 evidencia os resultados da Equação 4 para o período de 2010 a 2014. Nela, têm-se os valores dos coeficientes estimados, os coeficientes de determinação $\left(\mathrm{R}^{2}\right)$, a estatística F, a estatística do teste de normalidade de Jarque-Bera, a estatística do teste de homocedasticidade de White e, por fim, a estatística do teste de Wooldrigde. Os valores que se encontram entre parênteses correspondem ao $p$-valor de cada teste específico.

Os resultados da Tabela 10 evidenciam que a regressão para todos os modelos se mostrou significativa em termos estatísticos, ao nível de 1\%, conforme teste F. Além disso, verifica-se que a hipótese nula de homocedasticidade das variâncias foi rejeitada, ao nível de $1 \%$, para todos os modelos, assim como a hipótese nula de ausência de correlação serial. Dessa forma, os erros padrões foram estimados, usando Newey-West com 1 lag. Por fim, de acordo com o teste de Jarque-Bera, a hipótese nula de que os resíduos se distribuem normalmente foi rejeitada ao nível de $1 \%$. Entretanto, conforme o teorema do limite central e considerando-seque foram analisadas 942 observações, o pressuposto pode ser relaxado (BROOKS, 2008).Quanto aos coeficientes de determinação, tem-se que variam de 0,5371 a 0,5498 . 
Tabela 10 - Efeito da incerteza sobre o nível de investimento para o período de full IFRS

\begin{tabular}{|c|c|c|c|}
\hline Variáveis & $(\mathbf{a})^{1}$ & $(b)^{1}$ & $(c)^{1}$ \\
\hline \multirow[t]{2}{*}{ QTobin } & $0,0006^{* * *}$ & $0,0006 * * *$ & $0,0006^{* * *}$ \\
\hline & $(0,000)$ & $(0,000)$ & $(0,000)$ \\
\hline \multirow{2}{*}{ RGI } & $-0,0002 * * *$ & $-0,0002 * * *$ & $-0,0002 * * *$ \\
\hline & $(0,000)$ & $(0,000)$ & $(0,000)$ \\
\hline \multirow[t]{2}{*}{ RMC } & $0,0008 * * *$ & $0,0006 * *$ & $0,0008 * * *$ \\
\hline & $(0,000)$ & $(0,030)$ & $(0,001)$ \\
\hline \multirow{2}{*}{ END } & $0,0691 * * *$ & $0,0691 * * *$ & $0,0691 * * *$ \\
\hline & $(0,000)$ & $(0,000)$ & $(0,000)$ \\
\hline \multirow[t]{2}{*}{ INC_Total } & $-0,2161 * *$ & - & - \\
\hline & $(0,014)$ & & \\
\hline \multirow[t]{2}{*}{ INC_Mer } & - & $2,9983^{*}$ & 0,5159 \\
\hline & & $(0,070)$ & $(0,591)$ \\
\hline \multirow{2}{*}{ INC_Setor } & - & - & $-0,0181$ \\
\hline & & & $(0,977)$ \\
\hline \multirow[t]{2}{*}{ INC_Esp } & - & $-0,3506^{*}$ & $-0,3636 * *$ \\
\hline & & $(0,054)$ & $(0,046)$ \\
\hline \multirow[t]{2}{*}{ Intercepto } & $1,0328 * * *$ & $0,7829 * * *$ & $1,0726 * * *$ \\
\hline & $(0,000)$ & $(0,000)$ & $(0,000)$ \\
\hline $\mathbf{R}^{2}$ & 0,5371 & 0,5498 & 0,5371 \\
\hline \multirow[t]{2}{*}{ Teste F } & 23,77 & 24,18 & 22,78 \\
\hline & $(0,000)$ & $(0,000)$ & $(0,000)$ \\
\hline \multirow[t]{2}{*}{ Jarque-Bera } & $4,7 e+06$ & $4,4 e+06$ & $4,6 e+06$ \\
\hline & $(0,000)$ & $(0,000)$ & $(0,000)$ \\
\hline \multirow[t]{2}{*}{ White } & 510.06 & 641,79 & 675,90 \\
\hline & $(0,000)$ & $(0,000)$ & $(0,000)$ \\
\hline \multirow[t]{2}{*}{ Wooldridge } & 14,132 & 14,118 & 26,07 \\
\hline & $(0,000)$ & $(0,000)$ & $(0,000)$ \\
\hline Observações & 942 & 942 & 942 \\
\hline
\end{tabular}

Nota: (1) Erros padrões estimados com correção para heterocedasticidade e correlação serial usando Newey-West com 1 lag;

*** significante ao nível de $1 \%$;** significante ao nível de 5\%; * significante ao nível de $10 \%$.

No modelo (a), pode-se constatar que a incerteza total apresentou um efeito negativo e significativo sobre o nível de investimento, conforme esperado. Quanto ao modelo (b), observa-se que a incerteza de mercado teve um efeito positivo e significativo sobre o investimento, enquanto que a incerteza específica obteve um efeito negativo e significativo. Esses resultados corroboram o estudo de Bulan (2005) e Baum, Caglayan e Talavera (2008), para o mercado norte-americano, apesar de ser esperado um efeito negativo e significativo para incerteza de mercado. Destaca-se que, na regressão geral, no período de 2008 a 2014, Tabela 7, o efeito da incerteza de mercado não foi estatisticamente significativo.

No que concerne ao modelo (c), verifica-se que os resultados foram compatíveis com o da regressão geral, apresentando apenas a incerteza específica da firma como significativa estatisticamente e com um efeito negativo sobre o nível de investimento. Quanto às demais variáveis explicativas, os resultados também foram muito semelhantes ao da regressão geral, inclusive para as variáveis que não apresentaram o sinal esperado (RGI e END). 
Diante do exposto, verifica-se que, com exceção da variável INC_Mer do modelo (b), os demais resultados obtidos foram semelhantes aos da Tabela 7 para o marco temporal de 2008 a 2014. Portanto, tem-se que os resultados são robustos para o período pós IFRS.

\subsubsection{Medida alternativa de incerteza}

Para explorar a robustez dos resultados empíricos,utilizou-se uma proxy alternativa para a incerteza (INC_TA). Assim, a incerteza total da firma foi calculada pelo desvio padrão condicional do retorno das ações, conforme os estudos de Baum, Caglayan e Talavera (2008, 2010) e Tran (2014). A variância condicional do índice é estimada pelo modeloGARCH, empresa a empresa, ano a ano. Posteriormente, calcula-se o desvio padrão condicional, isto é, a raiz quadrada da variância condicional.

Destaca-se que foram utilizados o Critério de Informação Bayesiano (BIC) e o Critério de Informação de Akaike (AIC) para verificar o melhor ajuste do modelo GARCH. Os modelos testados foram: $\operatorname{GARCH}(1,1), \operatorname{GARCH}(1,2), \operatorname{GARCH}(2,1), \operatorname{GARCH}(2,2)$, $\operatorname{GARCH}(3,1), \operatorname{GARCH}(1,3), \operatorname{GARCH}(3,2), \operatorname{GARCH}(2,3)$ e $\operatorname{GARCH}(3,3)$. Nesse sentido, foram escolhidos os que apresentaram menor BIC/AIC. Geralmente, os critérios BIC e AIC conduzem ao mesmo resultado de avaliação, mas, quando houve diferença entre ambos, optou-se por observar o critério BIC.

Essa medida de incerteza total foi utilizada para o período de 2008 a 2014 (banco de dados geral), assim como para o período de fullIFRS.Contudo, antes de efetuar as regressões utilizando a medida alternativa de incerteza, verificou-se se a medida alternativa de incerteza total era endógena, isto é, se a proxy para incerteza era correlacionada com o termo de erro, conforme sugere o estudo de Bulan (2005).

Assim, na Tabela 11,são apresentados os resultados do teste de Durbin, teste F e teste de Wooldridge para os períodos analisados. Os instrumentos utilizados foram:a medida de incertezas total e específica da firma do primeiro modelo, para o período de 2008-2014, e para o período de Full IFRS a incerteza total do primeiro modelo e o $q$ de Tobin defasado.

De acordo com a Tabela 11, nota-se que a hipótese nula de que a variável é exógena foi rejeitada, segundo o teste de Durbin. Além disso, verifica-se que os instrumentos utilizados para testar a possível a endogeneidade são válidos, conforme o teste $\mathrm{F}$, e que os instrumentos utilizados não são correlacionados com o erro estrutural, segundo o teste de Wooldridge. 
Tabela 11 - Resultado dos testes de verificação de endogeneidade para a proxy alternativa de incerteza

\begin{tabular}{lccc}
\hline & Testes & $\mathbf{2 0 0 8 - 2 0 1 4}$ & Full IFRS \\
\hline Teste de Durbin & & 8,110 & 7,144 \\
& & $(0,004)$ & $(0,007)$ \\
Teste F & 108,847 & 50,720 \\
& & $(0,000)$ & $(0,000)$ \\
Wooldridge & 1,587 & 0,062 \\
& & $(0,208)$ & $(0,802)$ \\
\hline
\end{tabular}

Nota: Os valores que se encontram entre parênteses correspondem ao $p$-valor de cada teste específico.

Resumidamente, tem-se que a medida alternativa para incerteza total é endógena. Dessa forma, os parâmetros da Equação 4 foram regredidos pelo método de Mínimos Quadrados em Dois Estágios (MQ2E), uma vez que regredir por MQO apresentaria resultados enviesados e inconsistentes. Na Tabela 12, têm-se os resultados das regressões para o período de 2008-2014, bem como para o períodofull IFRS. Nela, constam os valores dos coeficientes estimados, o $\mathrm{R}^{2}$, a estatística de Wald, a estatística do teste de normalidade de Jarque-Bera, a estatística de heterocedasticidade de White e, por fim, a estatística do teste de autocorrelação de Wooldridge. Os valores que se encontram entre parênteses correspondem ao $p$-valor de cada teste específico.

Tabela 12 - Efeito da incerteza sobre o nível de investimento para o período de 20082014 e de full IFRScom proxy alternativa para incerteza

\begin{tabular}{|c|c|c|}
\hline VARIÁVEIS & $2008-2014^{1}$ & Full IFRS ${ }^{1}$ \\
\hline QTobin & $\begin{array}{l}0,0005^{* * * *} \\
(0,000)\end{array}$ & $\begin{array}{l}0,0006 \text { *** } \\
(0,000)\end{array}$ \\
\hline RGI & $\begin{array}{l}-0,0002 * * * \\
(0,000)\end{array}$ & $\begin{array}{l}-0,0002 * * * \\
(0,000)\end{array}$ \\
\hline RMC & $\begin{array}{l}0,0007 * * * \\
(0,000)\end{array}$ & $\begin{array}{l}0,0007 * * * \\
(0,000)\end{array}$ \\
\hline END & $\begin{array}{l}0,0456 \text { *** } \\
(0,000)\end{array}$ & $\begin{array}{l}0,0704 * * * \\
(0,000)\end{array}$ \\
\hline INC_TA & $\begin{array}{c}-10,665^{* *} * \\
(0,012)\end{array}$ & $\begin{array}{c}-12,9889 * * \\
(0,024)\end{array}$ \\
\hline Intercepto & $\begin{array}{l}1,4447 \\
(0,000)\end{array}$ & $\begin{array}{l}1,4447 \\
(0,000)\end{array}$ \\
\hline $\mathbf{R}^{2}$ & 0,3291 & 0,4856 \\
\hline Teste Wald & $\begin{array}{c}8.956,79 \\
(0,000)\end{array}$ & $\begin{array}{c}0,000 \\
(0,000)\end{array}$ \\
\hline Jarque-Bera & $\begin{array}{l}1,8 \mathrm{e}+06 \\
(0,000)\end{array}$ & $\begin{array}{c}1,4 \mathrm{e}+07 \\
(0,000)\end{array}$ \\
\hline White & $\begin{array}{l}615,11 \\
(0,000)\end{array}$ & $\begin{array}{l}830,93 \\
(0,000)\end{array}$ \\
\hline Wooldridge & $\begin{array}{c}1240,66 \\
(0,000)\end{array}$ & $\begin{array}{l}0,0000 \\
(0,000)\end{array}$ \\
\hline Observacões & 942 & 942 \\
\hline
\end{tabular}

Nota: (1) Erros padrões estimados com correção para heterocedasticidade e correlação serial usando Clusterizada Robusta para Empresa de Petersen (2009);

*** significante ao nível de $1 \%$;** significante ao nível de 5\%; * significante ao nível de $10 \%$. 
Assim, de acordo com Tabela 12, verifica-se que as regressões para os períodos analisados se mostraram significativas em termos estatísticos, ao nível de 1\%, conforme teste de Wald. Além disso, observa-se que a hipótese nula de homocedasticidade foi rejeitada, ao nível de 1\%, para ambos os períodos, assim como a hipótese nula de correlação serial, segundo os testes de White e Wooldridge, respectivamente. Sendo assim, os erros padrões foram estimados com correção para heterocedasticidade e correlação serial, usando Clusterizada Robusta para Empresa de Petersen (2009).

Quanto ao teste de Jarque-Bera, nota-se que a hipótese nula de que os resíduos se distribuem normalmente foi rejeitada, ao nível de 1\%. Entretanto, conforme o teorema do limite central e considerando que foram utilizadas 1.278 observações, o pressuposto pode ser relaxado (BROOKS, 2008). Por fim, observa-se que o coeficiente de determinação $\left(\mathrm{R}^{2}\right)$ para os períodos analisados possuem poder explicado de 0,3291 para o período de 2008-2014 e 0,4856 para o de fullIFRS. Esses resultados corroboram o da proxy principal para incerteza total, que foi de 0,3570 para o período de 2008-2014 e aumentou para 0,5371 para o de fullIFRS.

Ademais, verifica-se que, no período de 2008-2014, a incerteza total teve um efeito negativo e estatisticamente significativo sobre o nível de investimento das empresas, isto é, um aumento de $1 \%$ da incerteza total da firma diminui o nível de investimento em 10,66\%.Esses resultados são condizentes com os achados de Tran (2014) para empresas australianas. Além disso, também são condizentes com a TOR, uma vez que em elevados níveis de incerteza os administradores têm a opção de adiar um projeto de investimento a fim de obter mais informações sobre o investimento.

No que concerne ao período de fullIFRS, observa-se que não houve distinção "significativa" dos achados para o período de 2008-2014 com a proxy alternativa. No entanto, nota-se que o poder explicado da regressão aumentou, assim como o coeficiente da incerteza total, que passou de $-10,66$ para $-12,99 \%$.

Destaca-se que não foi feita a decomposição da incerteza total em seus componentes de risco de mercado, idiossincrático e específico da firma porque não foram encontrados instrumentos válidos para verificação de uma possível endogeneidade.

Em relação às demais variáveis explicativas, verifica-se que, em ambos os períodos, os resultados foram muito semelhantes aos da regressão das Tabelas 7 e 10, inclusive o sinal encontrado, com destaque para as variáveis RGI e END, que, assim como para as Tabelas 7 e 10, não apresentaram o sinal esperado na literatura. Uma possível justificativa para essas particularidades foram explicadas na seção 4.2. 
Diante do exposto, observou-se que, mesmo utilizando uma variável alternativa para incerteza total, os resultados encontrados foram semelhantes ao da primeira medida de incerteza utilizada neste estudo. 


\section{CONCLUSÃO}

Os métodos tradicionais para análise de investimento baseados emFCD levam em consideração apenas o risco sistemático (taxa de desconto ajustada ao risco) para análise dos seus investimentos. No entanto, a TOR defende que não é apenas o risco sistemático que influencia as decisões de investimento, mas sim a incerteza total do ambiente de negócio, isto é, as incertezas de mercado, do setor e específica da firma.

$\mathrm{Na}$ literatura internacional, existe uma extensa quantidade de estudos que analisam o efeito da incerteza sobre o comportamento dos investimentos (KELLOG, 2014; TRAN, 2014; KHALEGUI; PEYAMBARPEY; AMERI, 2015). Contudo, poucos trabalhos (BULAN, 2005; XU; WANG; XIN, 2010; KELLONG, 2014) buscaram analisar esse efeito sob a ótica das opções reais. Assim, esta dissertação teve como objetivo analisar o efeito da incerteza sobre o nível de investimento das empresas de capital aberto listadas na BM\&FBovespa, buscando justificar seu efeito sob a ótica das opções reais.

Para tanto, utilizou-se como medida de incerteza a volatilidade histórica do retorno das ações, segundo os estudos de Leahy e Whited (1996), Byrne e Davis (2005), Bulan (2005), Bloom, Bond e Reenen (2007), Adbul-Hanque e Shaoping (2008), Baum, Caglayan e Talavera (2008, 2010), Xu, Wwang e Xin (2010), Panousi e Papanikolaou (2012) e Tran (2014).Destaca-se que essa medida de incerteza total foi decomposta em seus componentes de risco (risco de mercado, risco idiossincrático e risco específico da firma), conforme os estudos de Bulan (2005) e Xu, Wang e Xin (2010). Além disso, uma medida alternativa de incerteza total foi utilizada, sendo calculada pelo desvio padrão condicional do retorno das ações por meio do modelo GARCH, conforme os estudos de Baum, Caglayan e Talavera $(2008,2010)$ e Tran (2014).

Assim, conforme os resultados obtidos, observou-seque a maioria das variáveis de incerteza utilizadas no estudo apresentaram poder explicativo quanto ao nível de investimento das organizações. Especificamente, as incertezas total e específica da firma tiveram um efeito negativo e significativo estatisticamente sobre o nível de investimento, sendo o efeito da incerteza específica superior ao da incerteza total.Diante dessas evidências, as hipóteses 2 e $2 b$, de que as incertezas total e específica da firma explicam parte das variações do nível de investimento no mercado brasileiro, não podem ser rejeitadas.Quanto à incerteza de mercado e a do setor, verificou-se que não apresentaram resultados estatisticamente significativos, portanto, as hipóteses 1 e $2 \mathrm{a}$, de que as incertezas de mercado e do setor explicam parte das variações do nível de investimento no mercado brasileiro, foram rejeitadas. 
Esses resultados comprovam que o efeito da incerteza sobre o nível de investimento das empresas é explicado pela TOR, uma vez que as incertezas que impactam o nível de investimento são as incertezas total e aespecífica da firma, conforme previsto pela TOR.

Adicionalmente, verificou-se que as empresas menores são mais sensíveis à incerteza, mudança do ambiente de negócio, do que as empresas maiores. Especificamente, as empresas maiores só sofreram impacto da incerteza específica da firma, ao nível de 10\%, enquanto que as empresas menores tiveram impacto das incertezas total e específica do setor, ao nível de $5 \%$. Esses resultados podem ser explicados devido às restrições financeiras que influenciam na viabilidade de novos investimentos, uma vez que as empresas menores têm maior restrição financeira, quando comparadasàs maiores. Logo, conclui-se que a incerteza desempenha um maior papel nas decisões de investimento de empresas financeiramente restritas.

Além disso, notou-se que as empresas mais competitivas sofrem um maior impacto da incerteza sobre o nível de investimento, quando comparadasàs menos competitivas. As empresas mais competitivas tiveram o impacto das incertezas total e específica, ao nível de $1 \%$,enquanto que as menos competitivas não obtiveram impacto estatisticamente significativo de qualquer dos tipos de incerteza. Os resultados obtidos contrariam o esperado, uma vez que, conforme a TOR, a concorrência deveria inibir a opção de adiar um investimento. Contudo, o fato de as empresas mais competitivas terem um maior impacto na incerteza pode ser justificado como uma particularidade do mercado brasileiro; os investidores podem evitar assumir grandes riscos para não terem prejuízo em novos investimentos, mesmo que para isso percam mercado.

Quanto ao período de fullIFRS, observou-se que os resultados encontrados foram muito semelhantes ao da regressão para o período de 2008 a 2012. No entanto, o coeficiente de determinação apresentou um melhor poder explicativo, passando, em média, de 0,3579 para 0,5413. Por fim, quanto à proxy alternativa de incerteza, percebeu-se, também, que os resultados não apresentaram divergências em relação à medida de incerteza calculada pela volatilidade histórica.

Dessa forma, de acordo com os resultados obtidos, verifica-se que existem evidências de que as incertezas total e específica da firma têm um efeito negativo sobre o nível de investimento das organizações no mercado brasileiro.Portanto, os administradores devem considerá-las quando da tomada de decisões. Esses resultados podem implicar nas finanças corporativas, quando da determinação da taxa de desconto, ao se analisar a viabilidade de novos projetos de investimentos. 
A principal contribuição teórica da pesquisa reside em trazer o debate do efeito da incerteza sobre o nível de investimento sob a ótica das opções reais, sobretudo com dados de mercados emergentes. Ademais, destaca-se que pesquisas nessa área são bastante incipientes no Brasil.

Ressalta-se que a presente pesquisa restringiu-se às empresas constituídas sob a forma de sociedade anônima, de capital aberto, com ações negociadas na BM\&FBovespa, no período de 2008 a 2014. Sendo assim, as conclusões obtidas ficam restritas à amostra utilizada.

Pesquisas futuras podem ser desenvolvidas explorando o efeito de outras proxies de incerteza sobre o nível de investimento. Além disso, sugere-se examinar o efeito da incerteza para despesas de capitais reversíveis e irreversíveis, que é uma aplicação direta da TOR. Assim seria possível analisar a estabilidade dos resultados obtidos nesta dissertação. 


\section{REFERÊNCIAS}

ABDUL-HAQUE; SHAOPING, W. Uncertainty and investment evidence from a panel of Chinese firms. Structural Change and Economic Dynamics,v.19,p.237-248, 2008.

AMRAM, M.; KULATILAKA, N. Strategy and shareholder value creation: the real options frontier. Journal of Applied Corporate Finance, v.13,n.2,p.15-29, 2000.

BAUM, C.; CAGLAYAN, M.; TALAVERA, O. Uncertainty determinants of firm investment. Economics Letters, v. 98, n. 3, p. 282-287, 2008.

On the sensitivty of firms' investiment to cash flow and uncertainty. Oxford Economic Papers-New Series, v. 62, n.2, p.286-306, 2010.

BEKOE, W.; ADOM, P. K. Macroeconomic uncertainty and private investment in Ghana: an empirical investigation. Jornal Internacional de Questões Econômicas e Financeiras, v. 3, n. 2,p.276-293, 2013.

BELL, G.; CAMPA, J. Irreversible investment and volatile markets: a study of the chemical processing industry. Review of Economics and Statistics,v. 114, n. 1, p. 320-29, 1999.

BLACK, F.; SCHOLES, M. The pricing of options and corporate liabilities. Journal of Political Economy, v. 81, n. 3, p. 637-654, 1973.

BLOOM, N.; BOND, S.; REENEN, J. V. Uncertainty and investment dynamics. Review of Economic Studies, v. 74, p. 391-415, 2007.

BONTEMPI, M. E.; GOLINELLI, R.; PARIGI, G. Why demand uncertainty curbs investment: evidence from a panel of Italian manufacturing firms. Journal of Macroeconomics, v. 32, n. 1, p. 218-238, 2010.

BRENNAN, M. J.; SCHWARTZ, E. S. Evaluating natural resource investments. Journal of Business, v. 58, n. 2, p. 135-157, 1985

BROOKS, C. Introductory econometrics for finance. Cambridge: Cambridge University Press, 2008.

BULAN, L. T. Firm investment behavior in a real options framework: empirical evidence. 2001. 128 f. Thesis (Doctor of Philosophy) - Graduate School of Arts and Science, Columbia University, Columbia, 2001.

BULAN, L. T. Real options, irreversible investment and firm uncertainty: new evidence from U.S. firms. Review of Financial Economics, v. 14, p. 255-279, 2005.

BULAN, L.; MAYER, C.; SOMERVILLE, C. T. Irreversible investment, real options, and competition: evidence from real estate development. Journal of Urban Economics, v. 65, n. 3, p. 237-251, 2009. 
BYRNE, J. P.; DAVIS, E. P. Investment and uncertainty in the G7.Review of World Economics, v. 141, n. 1, p. 1-32, 2005.

CABALLERO, R. J.; PINDYCK, R. S. Uncertainty, investment, and industry evolution. International Economic Review, v. 37, n. 3, p. 642-661, 1996.

CHUNG, K. H.; PRUITT S.W.A simple approximation of Tobin's Q. Financial Management, v. 23, n.3, p. 70-74, 1994.

CZARNITZKIZKI, D.; TOOLE, A. A. The R\&D investment-uncertainty relationship: do strategic rivalry and firm size matter? Managerial and Decision Economics, v. 34, n. 1, p. 15-28, 2013.

DIXIT, A.K.; PINDYCK, R.S. Investment under uncertainty. Princeton, New Jersey: Princeton University Press, 1994.

ESCALARES, M.; KOTTARIDI, C. The joint effect of macroeconomic uncertainty, sociopolitical instability, and public provision on private investment. The Journal of Developing Areas, v. 48, n. 1, p. 227-251, 2014.

EZZAHID, E.; EL ALAOUI, A.; BOUSSELHAMI, A.; HAMZAOOUI, M. Uncertainty and the dynamics of aggregate investment in Morocco. European Scientific Journal, v. 10, n. 13, p.169-190, 2014.

FAMA, E. F.; FRENCH, K. R. The cross-section of expected stock returns. Journal of Finance, v.47, p. 427-466, 1992.

GRAHAM, J. R.; HARVEY, C. R. The theory and practice of corporate finance: evidence from the field. Journal of Financial Economics, v. 60,p.187-243, 2001.

HAYASHI, F. Tobin's marginal q and average q: a neoclassical interpretation.

Econometrica, v. 50, n. 1, p. 213-224, 1982.

JENSEN, M.; MECKLING, W. Theory of the firm: managerial behavior, agency costs and ownership structure. Journal of Financial Economics, v. 3, n.4, p. 305-360, 1976.

KHALEGHI, F.; PEYAMBARPEY, S. A.; AMERI, M. The effect of exchange rate uncertainty on the effect of exchange rate uncertainty on private investment in Iran.Journal of Social Issues \& Humanities, v.3, n. 11, p. 136-143, 2015.

KELLONG, R. The effect of uncertainty on investment: evidence from Texas oil drilling. American Economic Review, v. 104, n. 6, p. 1698-1734, 2014.

LEAHY, J.; WHITED, T. The effect of uncertainty on investment: some stylized fact. Journal of Money, Credit, and Banking, v.28, p. 64-83, 1996.

LUEHRMAN, T. Investment opportunities as real options: getting started on the numbers. Harvard Business Review, p.51-67, jul./ago. 1998. 
MACHADO, M. A. V.; MEDEIROS, O. R. Modelos de precificação de ativos e o efeito liquidez: evidências empíricas no mercado acionário brasileiro. Revista Brasileira de Finanças, v.9, p. 383-412, 2011.

MCDONALD, R.; SIEGEL, D. The value of waiting to invest. Quarterly Journal of Economics, v. 101, p. 707-727, 1986.

MERTON, R. C. Theory of rational option pricing. The Bell Journal of Economics and Management Science, v. 4, n. 1, p. 141-183, 1973.

MINARDI, A. M. A. F. Teoria de opções aplicada a projetos de investimentos. RAE Revista de Administração de Empresa, São Paulo, v. 40, n. 2, p. 74-79, 2000.

MINTON, A. B.; SCHRAND, C. The impact of cash flow volatility on discretionary investment and the costs of debt and equity financing. Journal of Financial Economics, v. 54, p. 423-460, 1999.

MODIGLIANI, F.; MILLER, M. The cost of capital, corporation finance and the theory of investment. The American Economic Review, v. 48, n. 3, p. 261-297, 1958.

MOEL, A.; TUFANO, P. When are real option exercised?An empirical study of mine closings. Review of Financial Studies, v. 15, p. 35-64, 2002.

MYES, S. C. Determinants of corporate borrowing. Journal of Financial Economics,v.5, p. 147-175, 1977.

The capital structure puzzle. The Journal of Finance, v. 39, p. 575-592, 1984.

MYERS, S. C; MAJLUF, N. S. Corporate financing and investment decisions when firms have information that investors do not have. Journal of Financial Economics, v. 13, p. 187$221,1984$.

PANOUSI, V.; PAPANIKOLAOU, D. Investiment, idiosuncratic risk, and ownership. The Journal ofFinance,v. 67, n. 3, p.1113-1148,2012.

PEREIRA, R. M. Investment and uncertainty in machinery and real estate. RBE, v. 62, n. 3, p. 279-298, 2008.

PINDYCK, R. Investments of uncertain cost. Journal of Financial Economics. v. 34, p. 5374, 1993.

Irreversibility, uncertainty, and investment. Journal of Economic Literature, v. 29, n. 3, p. 1110-1148, 1991.

SÂMAN, C. Macroeconomic uncertainty and investment: empirical analysis for Romania. Romanian Journal of Economic Forecasting, v. 2, p. 155-164, 2010.

SANTOS, E. M.; PAMPLONA, E. O. Teoria das Opções Reais: uma atraente opção no processo de análise de investimentos. R.Adm., São Paulo, v.40, n.3, p.235-252, 2005. 
SARKAR, S. On the investment-uncertainty relationship in a real options model. Journal of Economic Dynamics \& Control, v.24, p. 219-225, 1999.

SCHWERT, G. W. Why does stock market volatility change over time? Journal of Finance, v. 44, p. $1115-1153,1989$.

SEABRA, F. A relação teórica entre incerteza cambial e investimento: os modelos neoclássico e de investimento irreversível. Pesquisa e Planejamento Econômico, v.26, n.2, p. 183-202, 1996.

TOBIN, J. A general equilibrium approach to monetary theory. Journal of Money, Credit and Banking, v. 1, n. 1, p. 15-29, 1969.

TOBIN, J.; BRAINARD, W. Pitfalls in Financial Model Building. American Economic Review, v. 58, n. 2, p. 99-122, 1968.

TRAN, T. L. Uncertainty and investment: evidence from Australian firm panel data. Economic Record, v. 90, p. 87-101, 2014.

TRIGEORGIS, L. Real options: managerial flexibility and strategy in resource allocation. Cambridge/Massachusetts: The MIT Press, 1996.

TRIGEORGIS, L. The nature of option interactions and the valuation of investments with multiple real options. The Journal of Financial and Quantitative Analysis, v. 28, n.1,p. 120, 1993.

TRUONG, G.; PARTINGTON, G.; PEAT, M. Cost-of-capital estimation and capitalbudgeting practice in Australia. Australian Journal of Management, v. 33, n.1, p.95-122, 2008.

XU, L.; WANG, J.;XIN, Y. Government control, uncertainty, and investment decisions in China's listed companies. China Journal of Accouting Research, v. 3, n. 1, p. 131-157, 2010. 